Research Paper

\title{
Re-expression of miR-200c suppresses proliferation, colony formation and in vivo tumor growth of murine claudin-low mammary tumor cells
}

\author{
Robert Jones $^{1}$, Katrina Watson ${ }^{1}$, Anthony Bruce ${ }^{1}$, Sarah Nersesian ${ }^{1}$, Jenna Kitz ${ }^{1}$, \\ Roger Moorehead ${ }^{1}$ \\ ${ }^{1}$ Department of Biomedical Science, Ontario Veterinary College, University of Guelph, Guelph, Ontario, Canada \\ Correspondence to: Roger Moorehead, email: rmoorehe@voguelph.ca \\ Keywords: microRNA, miR-200f, miR-200c, mammary tumors, claudin-low \\ Received: August 15, $2016 \quad$ Accepted: February 06, $2017 \quad$ Published: March 02, 2017
}

\section{ABSTRACT}

\begin{abstract}
Claudin-low breast cancer is a relatively rare breast cancer subtype. These cancers are typically ER-/PR-/HER2- and express high levels of mesenchymal genes as well as genes associated with inflammation, angiogenesis and stem cell function. In addition to alterations in gene expression, it was recently demonstrated that claudinlow breast cancers express very low levels of the miR-200 family of miRNAs. Given that each miRNA can regulate tens, hundreds or even thousands of genes, miRNAs are being evaluated as therapeutic targets. In this study we show that mammary tumors from MTB-IGFIR transgenic mice and cell lines derived from these tumors represent a model of human claudin-low breast cancer and murine claudin-low mammary tumors and cell lines express only very low levels of all five members of the miR-200 family. Reduced miR-200 family expression appears to be regulated via methylation as cells and tumors expressing low levels of miR-200 family members had higher levels of CpG methylation in a putative promoter region than tumors and cells expressing high levels of miR-200 family members. Re-expression of miR-200c in murine claudin-low mammary tumor cells inhibited tumor cell proliferation and colony formation in vitro and tumor growth in vivo. With respect to tumor growth in vivo, re-expression of miR-200c was associated with a reduction in tumor vasculature and expression of FIt1 and Vegfc. Therefore, miR-200c is an important regulator of mesenchymal tumor cell growth.
\end{abstract}

\section{INTRODUCTION}

MicroRNAs (miRNAs or miRs) are small non-coding RNA molecules approximately 19-22 nucleotides (nt) long $[1,2]$ that were originally identified in C. elegans in 1993 $[3,4]$. Subsequent studies on miRNAs determined that most miRNAs are initially transcribed as long primary transcripts (pri-miRNA) ranging from hundreds to thousands of nucleotides in length $[5,6]$. These pri-miRNAs are then processed in the nucleus by Drosha, a ribonuclease III endonuclease, resulting in a $\sim 60-80 \mathrm{nt}$ precursor transcript or pre-miRNA $[5,7,8]$. In the next step, pre-miRNAs are exported from the nucleus by Exportin 5 [8]. In the final step pre-miRNAs are cleaved into 19-22 nt double-stranded duplexes by another RNaseIII nuclease, Dicer $[5,9]$. Mature miRNAs are incorporated into a ribonucleoprotein complex known as the RNA-induced silencing complex
(RISC) [5]. Most miRNAs in mammals direct the RISC complex to target mRNAs and this complex binds to the 3'UTRs of mRNAs using the seed region (nucleotides 2-8) of the miRNA $[5,7,8,10,11]$. RISC complex binding to target mRNAs typically induce translational repression and mRNA destabilization $[5,7,8,10]$. Since only the seed region of miRNAs is required to bind mRNA, each miRNA can potentially regulate hundreds of mRNAs [12]. Several computational algorithms such as microRNA.org or TargetScan have now been developed that predict these potential mRNA targets [5]. Since there are over 2500 miRNAs identified in humans [13] and each miRNA can potentially regulate hundreds, or in some cases, thousands of mRNAs, miRNAs have been reported to regulate over $60 \%$ of the protein coding genes and thus represent one of the main classes of gene regulatory molecules in mammalian cells. 
Given that miRNAs regulate gene expression it is not surprising they can play a role in cancer development. When aberrantly expressed in cancer, miRNAs can act as tumour suppressors that repress oncogenic mRNAs, or as oncogenes that repress tumour suppressor genes $[12,14]$. One family of microRNAs that has garnered considerable attention in cancer biology is the miRNA-200 family (miR-200f) which consists of 5 members, miR-141, miR-200a, miR200b, miR-200c and miR-429. This family of microRNAs is expressed as two clusters on distinct chromosomes with the miR-200c/miR-141 cluster located on chromosome 12 in humans and chromosome 6 in mice and the miR-200b/miR200a/miR-429 cluster located on chromosome 1 in humans and chromosome 4 in mice [15]. The seed sequence, the region of the miRNA that determines mRNA binding, is the same in miR-200b, miR-200c, and miR-429 (AAUACUG). miR-200a and miR-141 share the same seed sequence (AACACUG) that is different from the seed sequence of miR-200b, miR-200c and miR-429 by one nucleotide [16]. Expression of the miR-200 clusters appears to be regulated by modifications to the promoter regions of each cluster. Promoter hypermethylation appears to be the primary mechanism for silencing miR-200c/141 expression while histone modifications via the Polycomb group has been reported to be responsible for silencing $\mathrm{miR}-200 \mathrm{~b} / 200 \mathrm{a} / 429$ expression [17].

The miR-200f regulates a number of properties important for cancer initiation and progression including epithelial-to-mesenchymal transition (EMT), proliferation, migration, and characteristics associated with stem/ progenitor cells [13, 18-22]. Several studies have shown that miR-200f members negatively regulate mesenchymal transcription factors such as Zeb1, Zeb2, Twist1, Twist2, Snail, and Snai2. These mesenchymal transcription factors repress E-cadherin transcription and genes that promote epithelial polarity [23-26] while inducing the expression of mesenchymal genes such as Vim and S100A4 [27, 28]. Therefore, loss of miR-200f members results in cells taking on a more mesenchymal phenotype potentially leading to enhanced migratory ability, increased metastatic potential and poorer patient prognosis. Consistent with it's role in EMT, studies in breast cancer have shown that the miR-200f is expressed in human luminal A breast cancers (tumor cells have epithelial characteristics) but lost in triple negative breast cancers including the claudin-low subtype (tumor cells have mesenchymal characteristics) [29, 30].

Claudin-low tumors were first described by Prat et al [31] and represent a subtype of triple-negative breast cancer characterized by high levels of markers associated with EMT such as Twist1, Twist2, Zeb1, Zeb2, Snai1, and Snai2 while expressing little or no markers of luminal differentiation [32]. In addition, claudin-low tumors express high levels of immune-related, angiogenesis and stem cell genes [31] and often display characteristics of metaplastic and medullary differentiation [33]. A subsequent study by Lehmann et al [34] identified 6 distinct subtypes of triple-negative breast cancer; basallike 1, basal-like 2, immunomodulatory, mesenchymal, mesenchymal stem-like and luminal androgen receptor. The mesenchymal stem-like subtype displayed low levels of claudin-3, -4 and -7 and thus have similar characteristics to claudin-low tumors. Finally, Jézéquel et al [35] identified 3 subtypes of triple-negative breast cancer; luminal androgen receptor, basal-like with low immune response and high M2 macrophages, and basal-enriched with high immune response and low M2 macrophages. Most of the claudin-low tumors were assigned to the basal-enriched with high immune response and low M2 macrophage subtype [35]. Since the nomenclature most appropriate for describing the different subtypes of triple negative breast cancer remains unresolved [35], this manuscript will use the term claudin-low to be consistent with prior publications on the tumors and cell lines derived from MTB-IGFIR transgenic mice [36-40].

Since one of the hallmarks of claudin-low breast cancer is the suppression of miR-200f members, this manuscript evaluated the impact of re-expressing a miR200f member, namely miR-200c, in murine mammary tumor cells with characteristics similar to human claudinlow breast cancer. Our findings indicate that miR-200c can suppress proliferation and colony formation of murine claudin-low tumor cells in vitro and impair tumor growth in vivo, potentially through inhibiting angiogenesis.

\section{RESULTS}

\section{miRNA expression in WT, PMT and RST samples}

A miRNA array was performed using an Agilent $8 \times 15 \mathrm{~K}$ v2:627 mouse miRNA array and 10 primary mammary tumor (PMT) samples and 6 recurrent spindle tumor (RST) samples. PMTs develop in transgenic mice due to elevated expression of the type I insulin-like growth factor receptor (IGF-IR) and these tumors have an epithelial appearance but cluster most closely with human basal-like breast cancers $[39,41,42]$. RSTs are mammary tumors that arise following downregulation of the IGF-IR transgene in established mammary tumors in MTB-IGFIR transgenic mice. RSTs have a mesenchymal morphology and cluster most closely with human claudin-low breast cancers [39, 41]. Detailed characterization of PMTs and RSTs have been previously described [39, 41, 42].

The top 15 differentially expressed microRNAs based on fold change $(\mathrm{p}<0.05)$ are presented in Table 1. The most differentially expressed miRNA was mmumiR-429, a member of the miR-200 family, and 4 of the 5 miR-200f members (miR-141, miR-200b, miR-200c and miR-429) were in the top 15 differentially expressed miRNAs (shaded in Table 1). Quantitative RT-PCR was used to validate the differential expression of the miR200 family and as shown in Table 2, all 5 members of 
Table 1: Top 15 microRNAs differentially expressed in PMTs vs RSTs based on fold change

\begin{tabular}{|c|c|}
\hline microRNA & $\begin{array}{l}\text { Fold Change } \\
\text { PMT vs RST }\end{array}$ \\
\hline mmu-miR-429 & 23.8 \\
\hline mmu-miR-290-5p & -20.8 \\
\hline mmu-miR-466f-5p & 19.0 \\
\hline mmu-miR-148a & 18.7 \\
\hline mmu-miR-685 & 18.0 \\
\hline mmu-miR-221 & -17.4 \\
\hline mmu-miR-211 & 16.9 \\
\hline mmu-miR-16* & 16.2 \\
\hline mmu-miR-503 & -16.2 \\
\hline mmu-miR-146a & -16.1 \\
\hline mmu-miR-200c & 14.6 \\
\hline mmu-miR-466h & 13.1 \\
\hline mmu-miR-141 & 11.7 \\
\hline mmu-miR-690 & -11.5 \\
\hline mmu-miR-200b & 11.4 \\
\hline
\end{tabular}

Table 2: miR-200f in PMTs and RSTs

\begin{tabular}{lcc}
\hline miRNA $^{1}$ & PMT & RST $^{2}$ \\
\hline miR-200a & 1 & $9.9 \times 10^{-3 *}$ \\
miR-200b & 1 & $1.4 \times 10^{-2 *}$ \\
miR-200c & 1 & $6.7 \times 10^{-3 *}$ \\
miR-141 & 1 & $4.6 \times 10^{-3 *}$ \\
miR-429 & 1 & $1.4 \times 10^{-2 *}$ \\
\hline
\end{tabular}

${ }^{1}$ normalized to SnoRNA202 and SnoRNA234.

${ }^{2}$ miRNA levels expressed relative to PMT.

$* \mathrm{p}<0.05$.

the miR-200f (miR-200a, miR-200b, miR-200c, miR-141 and miR-429) were expressed at significantly higher levels in the PMT samples compared to the RST samples. The magnitude of the difference of miR-200f members in PMT samples compared to RST samples detected by qRT-PCR was much greater than that detected by the miRNA array. All miR-200f members were expressed at least 70-fold higher in the PMT samples compared to the RST samples as determined by qRT-PCR (Table 2).

\section{Expression of miR-200c in RJ345, RJ348 and $\mathbf{R J 4 2 3}$ cells}

Cell lines have been generated from some of the PMTs and RSTs that developed in MTB-IGFIR transgenic mice. RJ345 cells were derived from a PMT and have epithelial morphology when grown as monolayers (Figure 1A, 1B), express the luminal epithelial gene $C d h 1$ [43] and express only very low levels of mesenchymal genes such as Twist1, Twist2, Zeb1, and Zeb2 [43]. In addition, this cell line is only weakly tumorigenic when injected into mammary fat pad of syngeneic FVB mice [43]. RJ348 cells were derived from a RST and have a mesenchymal morphology in culture, express low levels of Cdh1 and high levels of Twist1, Twist2, Zeb1, Zeb2 [43]. RJ348 cells are highly tumorigenic when injected into the mammary fat pad of syngeneic FVB mice [43]. One problem with the RJ348 cells is that they are difficult to stably transfect and thus another cell line with mesenchymal morphology, RJ423, was used in this study. RJ423 cells were derived 
from a different RST than RJ348 cells and RJ423 cells, like RJ348 cells have a mesenchymal morphology when grown as monolayer (Figure 1C, 1D).

Table 3 shows the expression of miR-200f members in RJ348 and RJ423 cells relative to RJ345 cells. RJ345 cells express all members of the miR-200f at levels significantly higher than either RJ348 or RJ423 cells. Therefore, the cell lines retain miR-200f expression profile of the tumors from which they were derived; both RJ345 and PMTs express high levels of miR-200f while RJ348, RJ423 and RSTs all express very low levels of miR-200f.
Figure 2 shows the expression of selected epithelial (Cdh1; Figure 2A) and mesenchymal (Snai1, Snai2, Twist1, Twsit2, Vim, Zeb1, Zeb2; Figure 2B-2H) genes in RJ345, RJ348 and RJ423 cells. RJ348 and RJ423 both express high levels of all the mesenchymal genes and only very low levels of $C d h 1$. Although RJ348 and RJ423 cells were both derived from RSTs and have similar morphology in culture, the levels of some of the mesenchymal genes did vary in that RJ423 cells had significantly higher levels of Twist2 and Zeb1 than RJ348 cells (Figure 2F, 2G) while RJ348 cells had significantly

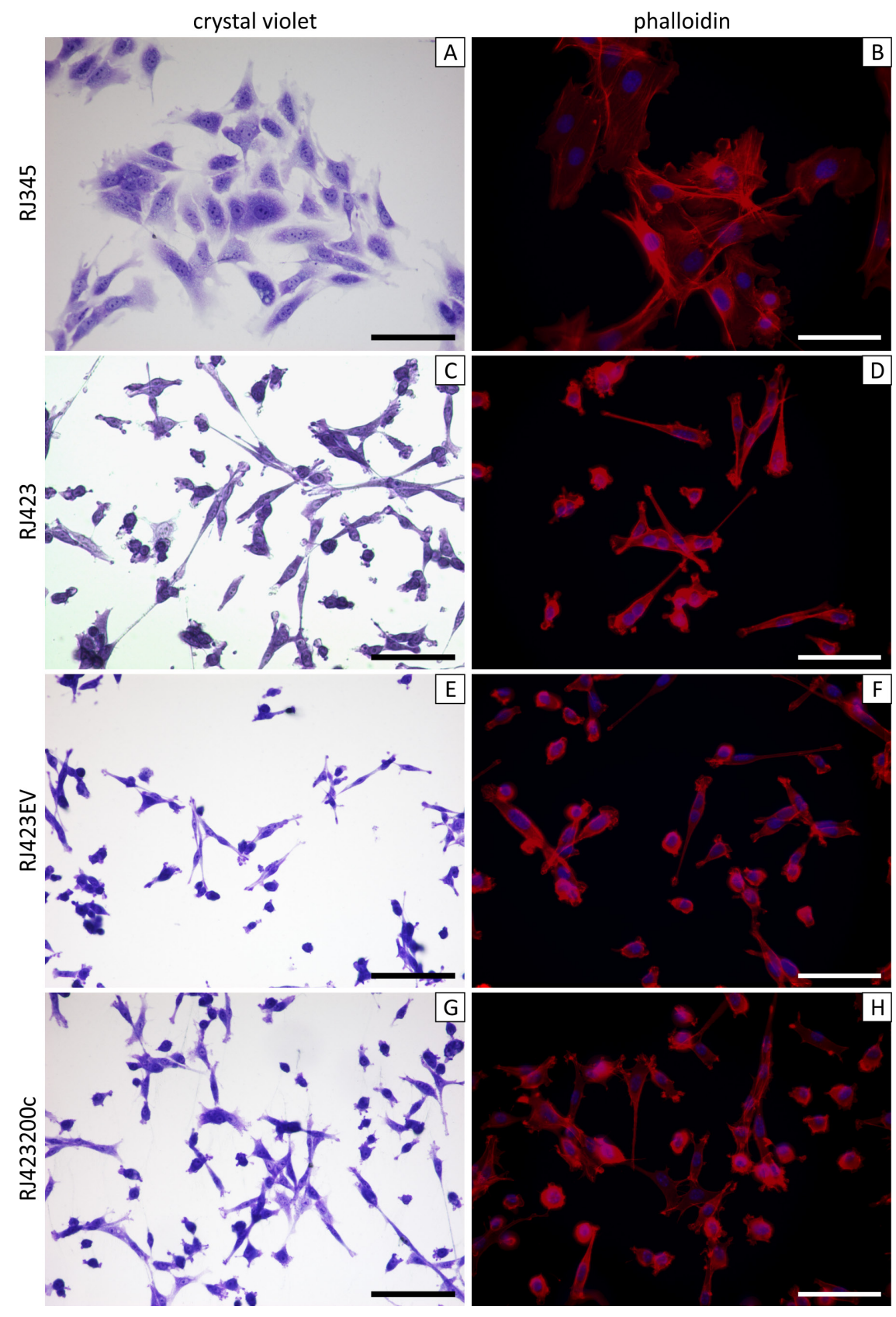

Figure 1: Representative images of crystal violet stained $(\mathbf{A}, \mathbf{C}, \mathbf{E}, \mathbf{G})$ and phalloidin stained (B,D,F,H). RJ345 (A,B), RJ423

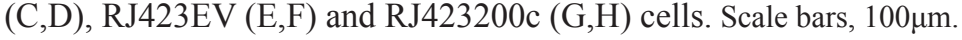


Table 3: miR-200f in RJ345, RJ348 and RJ423 cells

\begin{tabular}{lccc}
\hline miRNA $^{1}$ & RJ345 $^{1}$ & RJ348 $^{2}$ & RJ423 $^{2}$ \\
\hline miR-200a & 1 & $2.8 \times 10^{-5 *}$ & $9.3 \times 10^{-6 *}$ \\
miR-200b & 1 & $3.7 \times 10^{-5 *}$ & $3.7 \times 10^{-5 *}$ \\
miR-200c & 1 & $3.7 \times 10^{-4 *}$ & $3.2 \times 10^{-4 *}$ \\
miR-141 & 1 & $1.8 \times 10^{-4 *}$ & $8.4 \times 10^{-5 *}$ \\
miR-429 & 1 & ND $^{3 *}$ & ND $^{*}$ \\
\hline
\end{tabular}

${ }^{1}$ miRNA expression normalized to SnoRNA202 and SnoRNA234.

${ }^{2}$ miRNA levels expressed relative to RJ345 cells.

${ }^{3} \mathrm{ND}$ - not detected.

$* \mathrm{p}<0.05$.
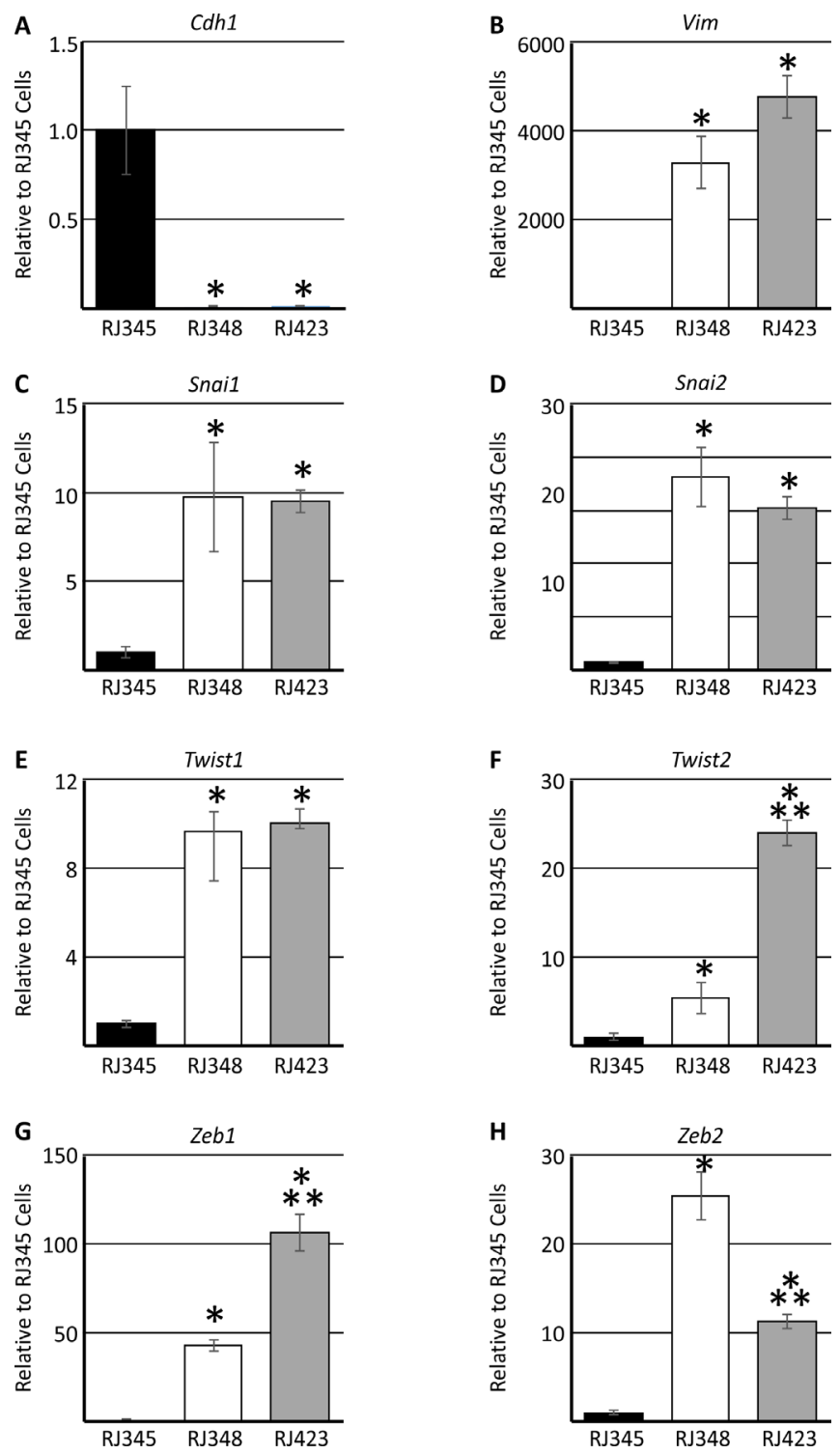

Figure 2: Expression (mean \pm SEM) of E-cadherin/Cdh1 (A), vimentin/Vim (B), Snail/Snail (C), Slug/Snai2 (D), Twist1 (E), Twist2 (F), Zeb1 (G) and Zeb2 (H) as determined by qRT-PCR. Gene expression in RJ348 and RJ423 cells are expressed relative to RJ345 cells. Hprt was used as the housekeeping gene and * indicates significant difference $(\mathrm{p}<0.05)$ in RJ348 and RJ423 cells compared to RJ345 cells while ** indicates significant differences $(\mathrm{p}<0.05)$ between RJ348 and RJ423 cells. Each cell line represents $\mathrm{n}=3$. 
higher levels of Zeb2 than RJ423 cells (Figure 2H). Both RJ348 and RJ423 cells expressed only extremely low levels of Cldn3, Cldn4 and Cldn7 (data not shown) suggesting that both RJ348 and RJ423 cells share features of human claudin-low breast cancers.

\section{miR-200c is regulated by promoter methylation}

Previous reports indicate that the miR-200c/ miR-141 promoter region can be methylated and this methylation decreases miR-200c and miR-141 expression [44-47]. To assess miR-200c promoter methylation in our model systems two approaches were employed. First, targeted bisulfite sequencing of a putative miR-200c/miR141 promoter region was performed in RJ345, RJ423 and RJ348 cell lines as well as in PMT and RST samples. Thirty-three $\mathrm{CpG}$ sites within a region $\sim 1000 \mathrm{bp}$ upstream of the miR-200c/miR-141 start site were evaluated. Of the $33 \mathrm{CpG}$ sites, $30 \mathrm{CpG}$ sites had at least $10 \mathrm{read}$ counts in all three cell lines and tumor tissue. At each
$\mathrm{CpG}$ site, the total $\mathrm{CpG}$ count and the methylated $\mathrm{CpG}$ count were determined and these values were used to calculate a methylated $\mathrm{CpG}$ ratio. Figure $3 \mathrm{~A}$ shows the methylated $\mathrm{CpG}$ ratio of the $30 \mathrm{CpG}$ sites with high read counts in a graphical representation where each individual pie represents a distinct $\mathrm{CpG}$ site. If the average $\mathrm{CpG}$ methylation ratio was $<5 \%$ the pie appears completely white. Average $\mathrm{CpG}$ methylation ratio of $5-25 \%$ was indicated by one quarter of the pie being shaded black while $\mathrm{CpG}$ methylation ratios of $26-50 \%$ and $51-75 \%$ represent one half and three quarters of the pie being shaded black, respectively. If the $\mathrm{CpG}$ methylation ratio was $>75 \%$ the entire pie was shaded black. As shown in Figure 3A the level of methylation was higher in RJ423 and RJ348 cells compared to RJ345 cells and 29/30 sites in RJ423 cells and 28/30 sites in RJ348 reached statistical significance. $\mathrm{CpG}$ methylation was also higher in RST samples compared to PMT samples and $\mathrm{CpG}$ methylation ratio was statistically higher in $29 / 30$ of the sites.

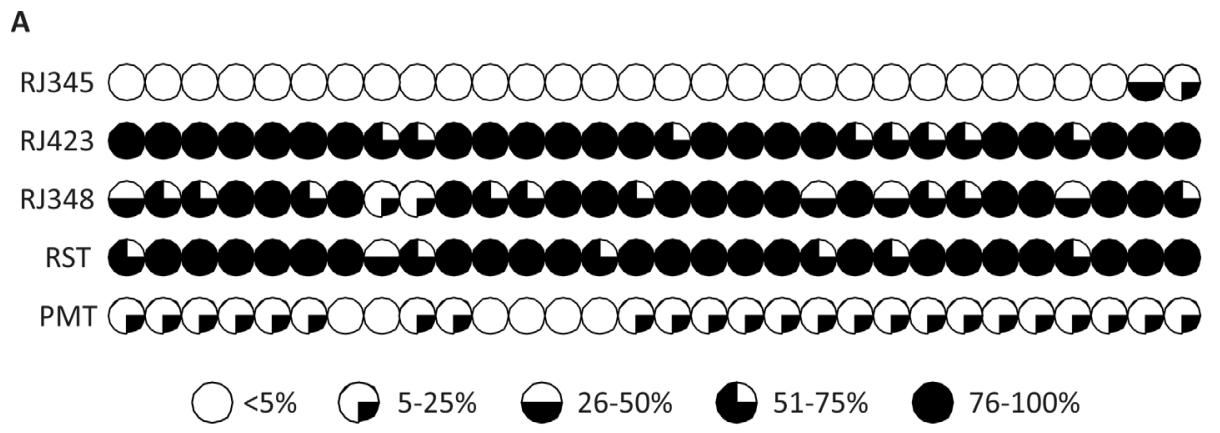

B

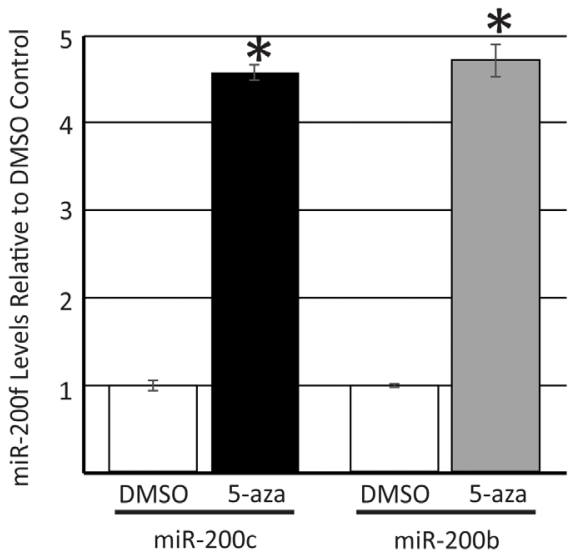

Figure 3: Evaluation of the methylation status of $30 \mathrm{CpG}$ sites $\sim 1000 \mathrm{bp}$ upstream of the miR-200c/miR-141 cluster on murine chromosome 6 as determined by targeted bisulfite sequencing. Each $\mathrm{CpG}$ site is represented by an individual pie and percentage of $\mathrm{CpG}$ sites methylated are indicated by the amount of shading; $<5 \%$ methylation, $\bigcirc, 5-25 \%$ methylation, , 26-50\% methylation, $-51-75 \%$ methylation, - and $>75 \%$ methylation, (A). miR-200c and miR-200b (first miRNA in miR$200 \mathrm{c} / 141$ or miR-200b/200a/429 cluster) levels in RJ423 cells treated daily with DMSO or $3 \mu \mathrm{M}$ of the DNA methyltransferase inhibitor, 5-aza-2'-deoxycytidine (5-aza) for 72hrs (B). Each bar represents the mean \pm SEM of 3 independent trials, ${ }^{*} \mathrm{p}<0.05$. 
In the second approach, RJ423 cells were treated with the DNA methyltransferase inhibitor, 5-aza-2'deoxycytidine for 72 hours. Treatment of cells with 5-aza-2'-deoxycytidine has been shown to reduce DNA methylation and increase expression of microRNAs regulated by methylation [44]. Figure 3B shows the levels of the first member of each miR-200f cluster (miR-200c and miR-200b) in RJ423 cells treated with the vehicle control (DMSO) or 5-aza-2'-deoxycytidine. 5-aza-2'deoxycytidine treatment significantly increased the expression of both miR-200c (4.6-fold) and miR-200b (4.7-fold) suggesting that the expression of both miR-200 clusters are regulated, at least in part, by methylation.

\section{Re-expression of miR-200c in $\mathrm{RJ} 423$ cells}

To determine the function of miR-200f in murine mammary tumor cells with features of human claudin-low breast cancer, miR-200c was re-expressed in RJ423 cells. As mentioned above, RJ423 cells were selected as it is easier to stably transfect these cells than the RJ348 cells. We also chose to re-express only one miR-200f member to simplify the data analysis. It should be noted that although only miR-200c was re-expressed in RJ423 cells, miR-200c has hundreds of predicted mRNA targets (microrna.org, targetscan.org, mirdb.org).

RJ423 cells were transfected with either the control plasmid (pCMV-MIR) creating RJ423EV cells or a plasmid expressing miR-200c driven by a CMV promoter (pCMV-MIR containing the miR-200c) creating RJ423200c cells. TaqMan RT-PCR revealed that the RJ423200c cells expressed significantly higher levels of miR-200c compared to RJ423EV cells ( $>300$-fold increase in miR-200c levels) and the level of miR-200c expression in the RJ423200c cells was nearly restored to the levels expressed by RJ345 cells (Figure 4). None of the other

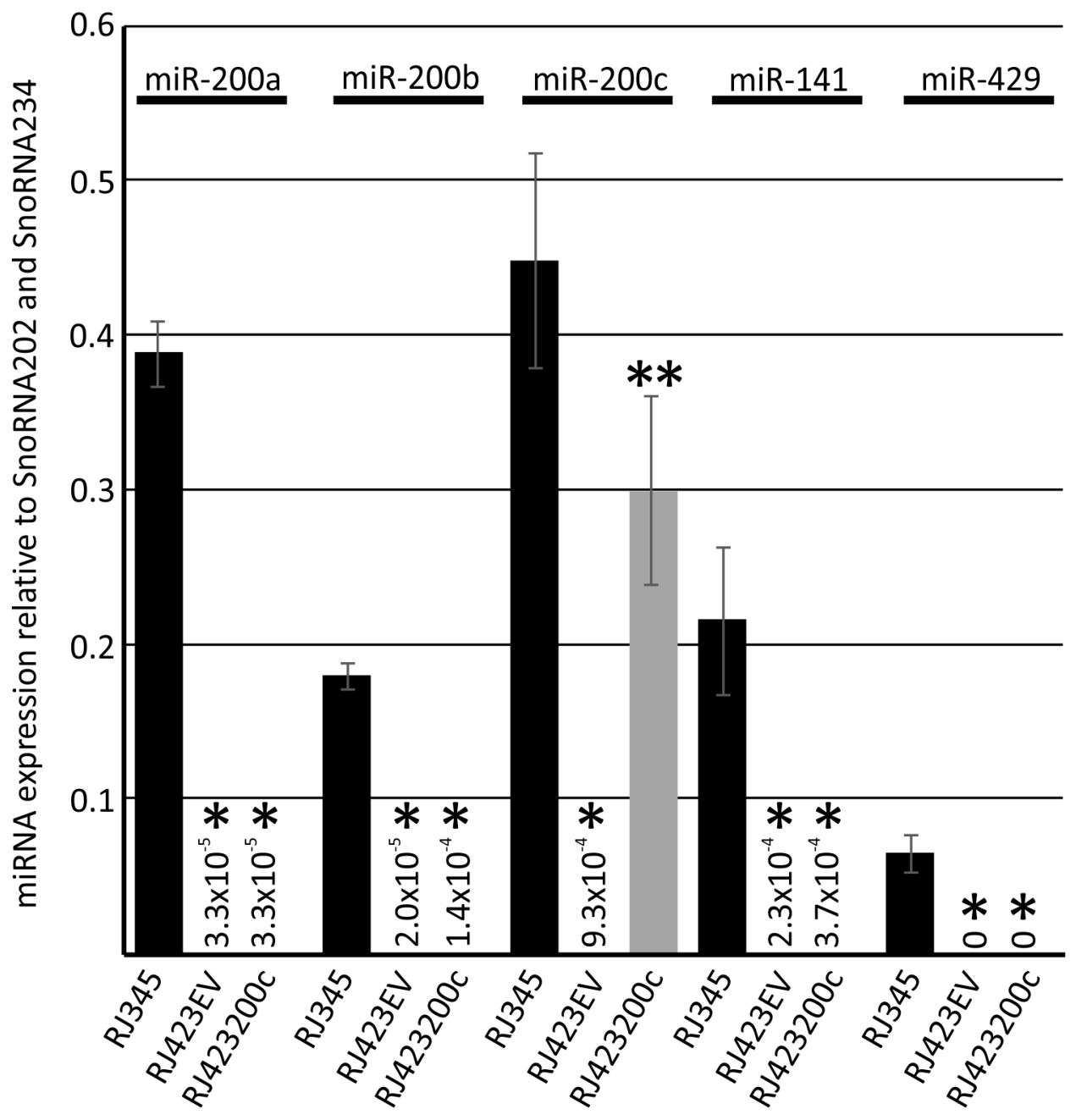

Figure 4: Expression (mean \pm SEM) of miR-200a, miR-200b, miR-200c, miR-141 and miR-429 in RJ345 cells, RJ423 cells containing the empty vector control (RJ423EV) or RJ423 cells containing miR-200c (RJ423200c) as determined by Taqman RT-PCR. The expression of each miRNA was normalized to the levels of SnoRNA202 and SnoRNA234. *indicates significant difference $(p<0.05)$ in RJ4232EV and RJ423200c cells compared to RJ345 cells while **indicates significant differences $(p<0.05)$ between RJ423EVand RJ423200c cells. Each cell line represents n $\geq 3$. 
miR-200f members were elevated in the RJ423200c cells indicating that miR-200c was specifically upregulated in these cells (Figure 4).

Re-expression of miR-200c in RJ423200c cells only had a modest effect on mesenchymal gene expression (Figure 5A-5H) and only Twist1 was significantly downregulated in RJ423200c cells compared to RJ423EV cells
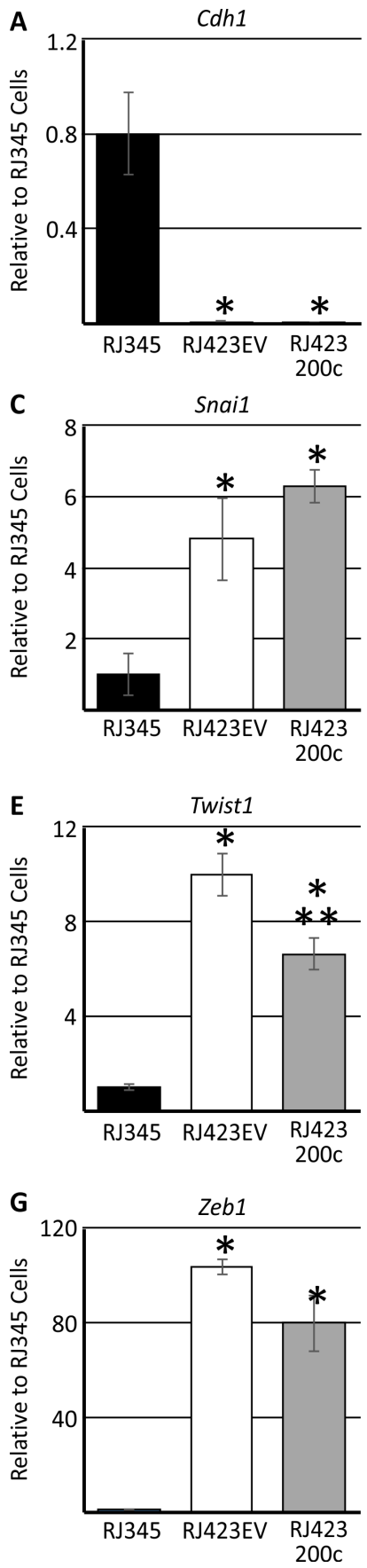

(Figure 5E). Zeb2 expression was approximately 40\% lower in the RJ423200c cells compared to RJ423EV cells but this change did not reach significance $(p=0.08)$. The modest change in mesenchymal gene expression was not overly surprising considering RJ423200c cells grown as monolayers retained a cell morphology more similar to RJ423 cells than RJ345 cells (Figure $1 \mathrm{G}, \mathrm{H}$ ).
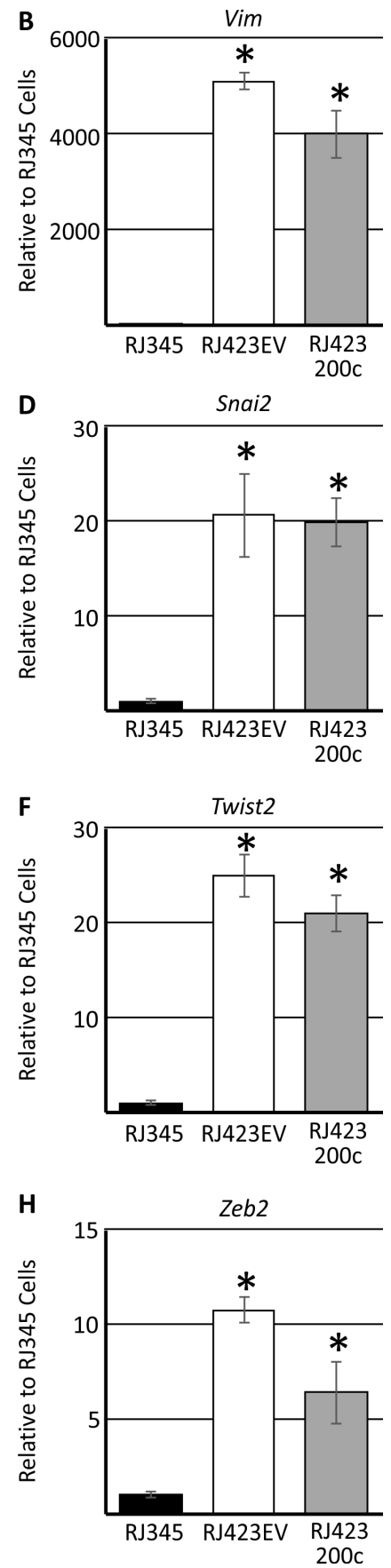

Figure 5: Expression (mean \pm SEM) of E-cadherin/Cdh1 (A), vimentin/Vim (B), Snail/Snai1 (C), Slug/Snai2 (D), Twist1 (E), Twist2 (F), Zeb1 (G) and Zeb2 (H) as determined by qRT-PCR. Gene expression in RJ423EV and RJ423200c cells are expressed relative to RJ345 cells. Hprt was used as the housekeeping gene and * indicates significant difference $(\mathrm{p}<0.05)$ in RJ4232EV and RJ423200c cells compared to RJ345 cells while ** indicates significant differences $(p<0.05)$ between RJ423EV and RJ423200c cells. Each cell line represents $n=3$. 


\section{Re-expression of miR-200c impairs cell proliferation and anchorage independent growth but not invasion in vitro}

Proliferation was determined using phosphohistone H3 immunofluorescence in RJ345, RJ423EV and RJ423200c cells. As shown in Figure 6A, RJ423EV cells had a significantly higher percentage of cells staining positive for phospho-histone H3 than RJ345 cells. Re- expression of miR-200c in RJ423 cells significantly reduced cell proliferation compared to RJ423EV cells. These findings suggest that expression of miR-200c negatively impacts cell proliferation rates.

Apoptosis was determined using immunofluorescence for cleaved caspase 3 and there were no significant differences identified and RJ345, RJ423EV and RJ423200c cells and all cell lines had less than $0.25 \%$ of the cells stain positive for cleaved caspase 3 (data not shown).

\section{A}

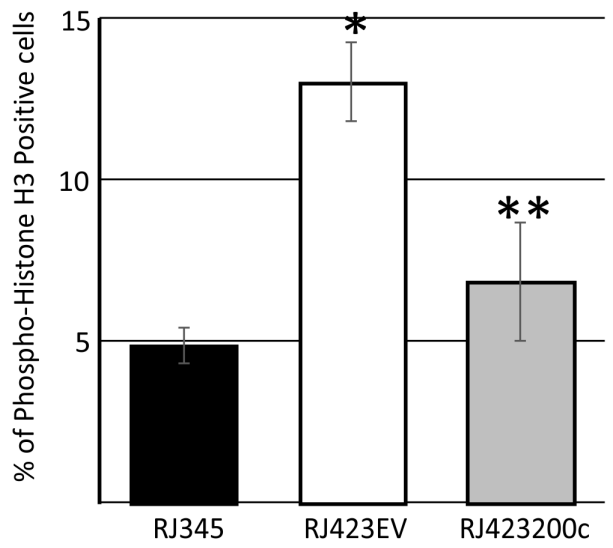

B
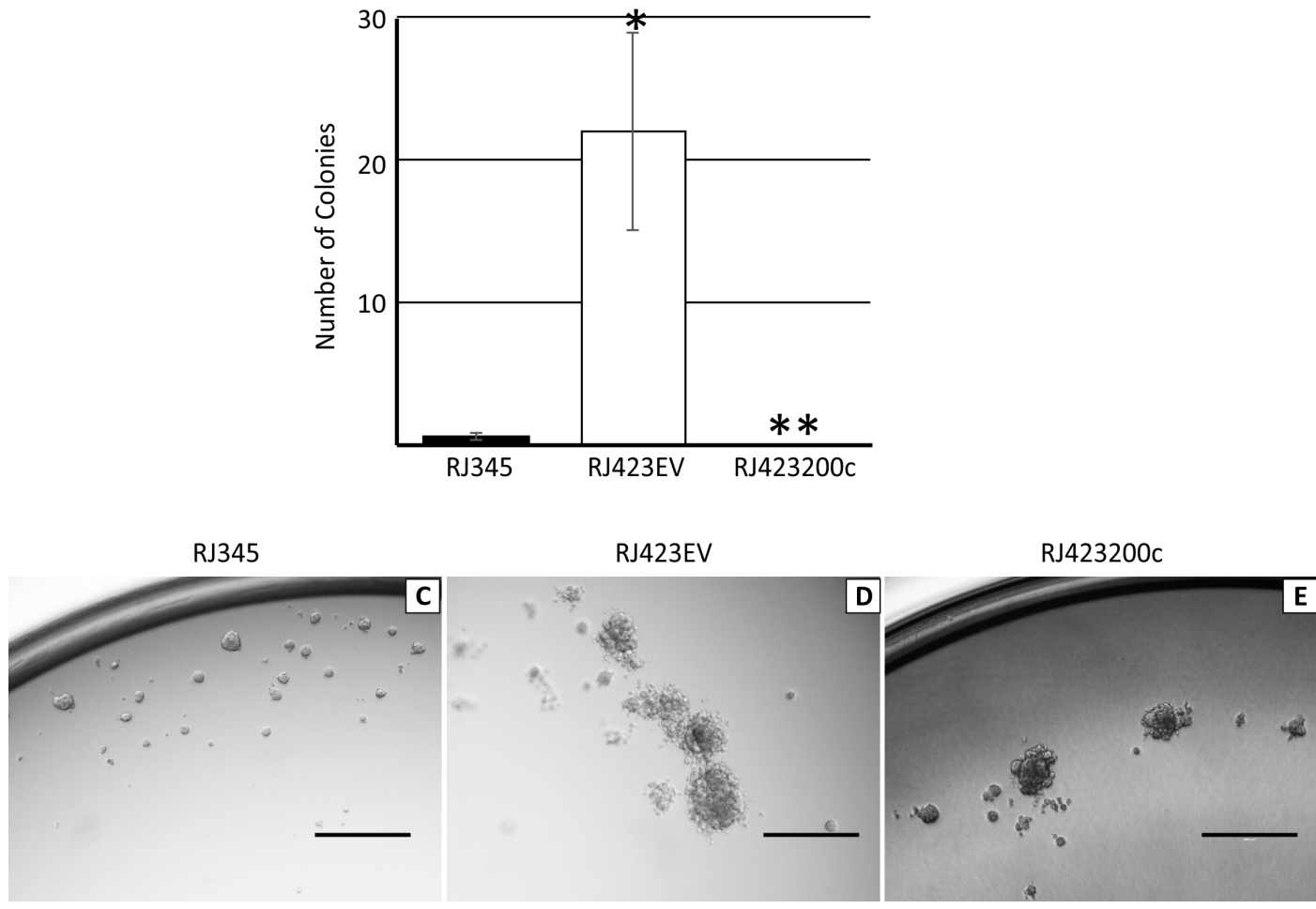

Figure 6: Quantification (mean \pm SEM) of immunohistochemistry for phospho-histone H3 (A) or colony formation in soft agar (B) in RJ345, RJ423EV and RJ423200c cells. * indicates significant difference ( $<<0.05)$ in RJ4232EV and RJ423200c cells compared to RJ345 cells while ** indicates significant differences $(\mathrm{p}<0.05)$ between RJ423EV and RJ423200c cells. Each cell line represents $\mathrm{n}=3$. Images in C-E are representative colonies formed by RJ345 (C), RJ423EV (D) and RJ423200c (E) cells when grown as three dimensional cultures in matrigel. Scale bar, $400 \mu \mathrm{m}$. 
To determine the ability of RJ345, RJ423EV and RJ423200c cells to grow under anchorage independent growth conditions these cells were grown suspended in agar. Under these conditions, RJ423EV cells produced significantly more colonies than RJ345 cells while reexpression of miR-200c in RJ423200c completely abolished the ability of RJ423 cells to produce colonies in a soft agar assay (Figure 6B).

RJ345, RJ423EV and RJ423200c cells were also grown suspended in matrigel. In matrigel, RJ345 cells formed compact, dense spheres with defined borders (Figure 6C) while RJ423EV formed were more loosely organized spheres with irregular borders (Figure 6D). RJ423200c spheres appeared to be densely packed but possessed irregular borders and thus shared characteristics with both RJ345 cells and RJ423EV cells (Figure 6E).

Cell migration was determined using an invasion chamber assay. As shown in Figure 7 significantly more RJ423EV cells migrated through the matrigel-coated invasion chambers than RJ345 cells demonstrating that the mesenchymal RJ423EV cells had superior invasive potential compared to the luminal RJ345 cells. Reexpression of miR-200c in RJ423 cells did not significantly reduce cell invasion as RJ423EV and RJ423200c cells had similar invasive properties.

\section{RNA sequencing}

To further understand the genetic alterations induced by re-expression of miR-200c in RJ423 cells, RNA sequencing was performed on RJ423EV and RJ423200c cells using 3 independent replicates for each cell line. When the list of genes was filtered for log fold change $>1$ and DESeq adjusted p-value of $<0.01,305$ genes met these criteria (137 upregulated and 168 downregulated genes). The top 20 genes based on p-value are listed in Table 4.

Advaita's iPathwayGuide software (Advaita Corporation, Plymouth, MI) was used to identify cellular pathways and functions associated with the differentially expressed genes. The two significant biological pathways and top 5 molecular functions identified by iPathwayGuide are presented in Table 5. This software was also used to identify genes downregulated in RJ423200c cells compared to RJ423EV cells that had miR-200c consensus sequences as predicted by iPathwayGuide software. This analysis identified 5 potential miR-200c targets and these targets are listed in Table 6. Quantitative RTPCR confirmed that these 5 genes were significantly downregulated in RJ423200c cells compared to RJ423EV cells (Table 6).
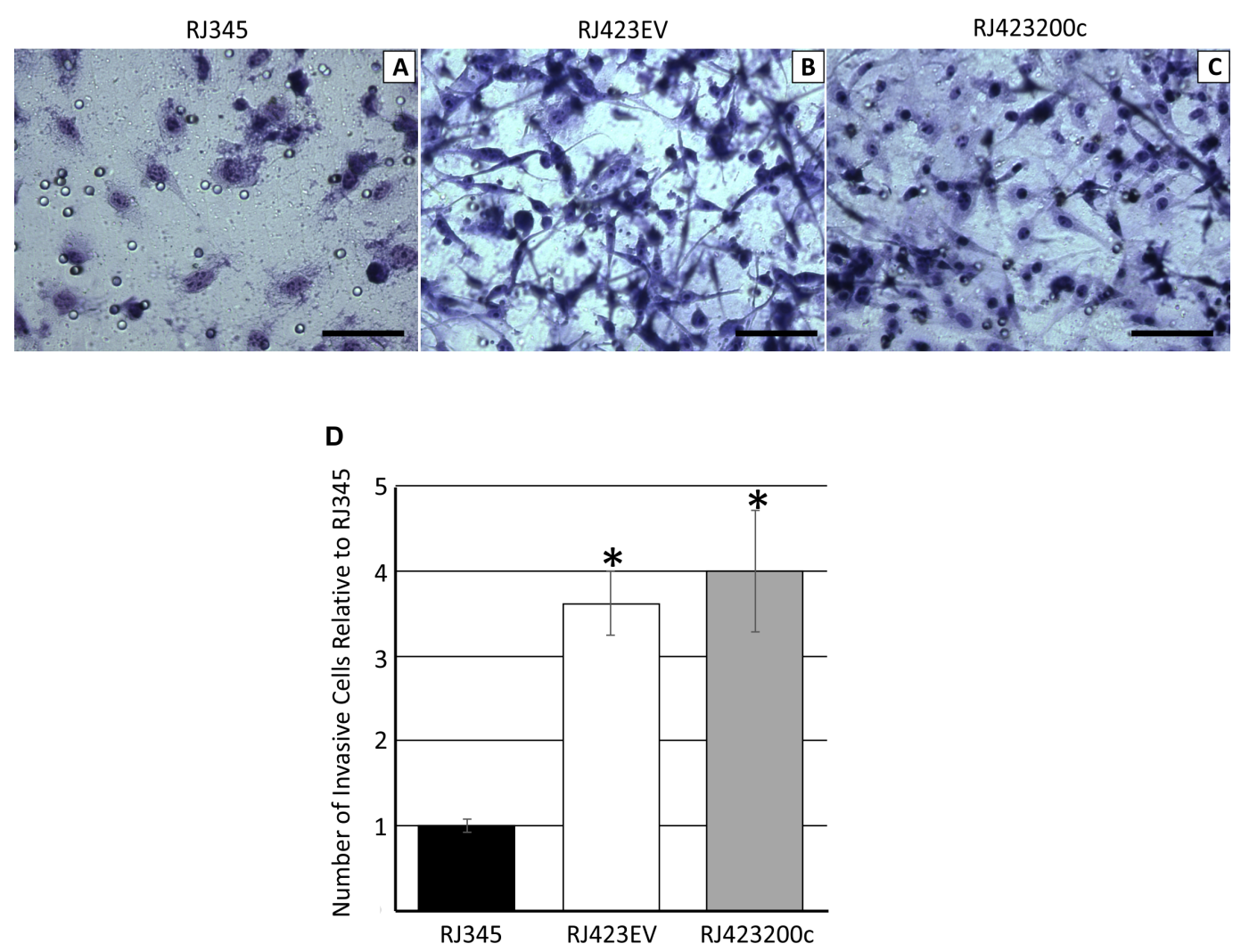

Figure 7: Representative images of RJ345 (A), RJ423EV (B) and RJ423200c (C) cells that migrated through the invasion chamber following fixation and staining. Scale bars, $100 \mu \mathrm{m}$. Panel (D) shows the quantification of the number of cells that migrated through the invasion chamber for RJ423EV and RJ42300c cells relative to RJ345 cells. The graph represents the mean and SEM of at least 3 individual trials. * indicates significant difference $(\mathrm{p}<0.05)$ in RJ4232EV and RJ423200c cells compared to RJ345 cells. 
Table 4: Genes differentially expressed in RJ423200c cells compared to RJ423EV cells

\begin{tabular}{|c|c|c|c|}
\hline Gene ID & Gene Symbol & Log Fold Change ${ }^{1}$ & Deseq Adjusted pval \\
\hline ENSMUSG00000073599 & Ecscr & -5.0 & $2.2 \times 10^{-55}$ \\
\hline ENSMUSG00000070867 & $\operatorname{Tr} a b d 2 b$ & 4.5 & $5.2 \times 10^{-46}$ \\
\hline ENSMUSG00000041078 & Grid1 & -3.2 & $1.0 \times 10^{-44}$ \\
\hline ENSMUSG00000092060 & Bend4 & -7.7 & $2.5 \times 10^{-44}$ \\
\hline ENSMUSG00000029810 & Tmem176b & -8.8 & $3.2 \times 10^{-39}$ \\
\hline ENSMUSG00000023367 & Tmem176a & -9.8 & $1.5 \times 10^{-32}$ \\
\hline ENSMUSG00000024598 & Fbn2 & 4.3 & $5.1 \times 10^{-28}$ \\
\hline ENSMUSG00000046159 & Chrm3 & -2.7 & $1.7 \times 10^{-26}$ \\
\hline ENSMUSG00000025876 & $U n c 5 a$ & -2.2 & $4.8 \times 10^{-25}$ \\
\hline ENSMUSG00000049404 & Rarres 1 & -2.6 & $2.2 \times 10^{-24}$ \\
\hline ENSMUSG00000037762 & Slc16a9 & -5.8 & $1.5 \times 10^{-21}$ \\
\hline ENSMUSG00000024743 & Syt7 & -4.7 & $2.8 \times 10^{-21}$ \\
\hline ENSMUSG00000060044 & Tmem26 & -2.3 & $8.9 \times 10^{-20}$ \\
\hline ENSMUSG00000027797 & Dclk1 & -2.1 & $3.1 \times 10^{-19}$ \\
\hline ENSMUSG00000060600 & Eno3 & -1.7 & $4.1 \times 10^{-19}$ \\
\hline ENSMUSG00000036862 & Dchs1 & 2.2 & $1.2 \times 10^{-18}$ \\
\hline ENSMUSG00000054612 & Mgmt & -7.1 & $1.6 \times 10^{-18}$ \\
\hline ENSMUSG00000032334 & Loxl1 & 1.6 & $3.4 \times 10^{-18}$ \\
\hline ENSMUSG00000036585 & $F g f 1$ & 3.9 & $5.6 \times 10^{-17}$ \\
\hline ENSMUSG00000074151 & Nlrc5 & -1.8 & $2.5 \times 10^{-16}$ \\
\hline
\end{tabular}

${ }^{1}$ negative log fold change indicate genes downregulated in RJ423200c cells relative to RJ423EV cells.

Table 5: Pathways and functions identified by ipathwayguide

\begin{tabular}{lc}
\hline Biological Pathway & Pval \\
Transcriptional misregulation in cancer & 0.043 \\
Neuroactive ligand-receptor interaction & 0.043 \\
Molecular Functions & 0.02 \\
Protein-arginine deiminase activity & 0.02 \\
Receptor binding & 0.02 \\
Receptor activity & 0.02 \\
Molecular transducer activity & 0.02 \\
Signaling receptor activity & \\
\hline
\end{tabular}

Table 6: genes downregulated in RJ423200c cells with potential miR-200c target sequences

\begin{tabular}{|c|c|c|c|c|}
\hline Gene ID & Gene Symbol & $\begin{array}{l}\text { Log Fold Change } \\
{\text { (RNA-Seq })^{1}}^{1}\end{array}$ & Deseq Adjusted pval & $\begin{array}{c}\text { Log Fold Change } \\
\left(\text { RT-PCR) }{ }^{1}\right.\end{array}$ \\
\hline ENSMUSG00000031355 & Arhgap6 & -1.3 & $2.8 \times 10^{-7}$ & -1.1 \\
\hline ENSMUSG00000045103 & Dmd & -5.8 & $2.6 \times 10^{-4}$ & -6.6 \\
\hline ENSMUSG00000029648 & Flt1 & -1.2 & $1.7 \times 10^{-9}$ & -1.2 \\
\hline ENSMUSG00000059336 & Slc14a1 & -3.6 & $1.8 \times 10^{-4}$ & -3.9 \\
\hline ENSMUSG00000024924 & Vldlr & -1.5 & $1.4 \times 10^{-3}$ & -1.3 \\
\hline
\end{tabular}

${ }^{1}$ negative log fold change indicate genes downregulated in RJ423200c cells relative to RJ423EV cells. 


\section{Re-expression of miR-200c impairs mammary tumor growth in vivo}

To determine whether re-expression of miR-200c in RJ423 cells affected mammary tumor growth in vivo, RJ423EV and RJ423200c cells were injected into the $4^{\text {th }}$ mammary glands of wild type, FVB mice. Two different cell numbers were injected for both RJ423EV and RJ423200c cells; $5 \times 10^{5}$ and $5 \times 10^{4}$ cells per mammary gland. Tumor development was similar following injection of either $5 \times 10^{5}$ or $5 \times 10^{4}$ cells and thus, the data from the different cell numbers was pooled. Injection of RJ345 cells was not performed as our previous studies demonstrated that RJ345 cells are only weakly tumorigenic (only $50 \%$ of the mammary gland injected with $2.5 \times 10^{6} \mathrm{RJ} 345$ cells produced tumors and injection of $5 \times 10^{5}$ RJ345 cells failed to produce mammary tumors [40]). In contrast, $100 \%$ of the injections with either $5 \times 10^{5}$ or $5 \times 10^{4}$ cells for either RJ423EV or RJ423200c cells produced mammary tumors.

The images in Figure 8A show representative tumors following injection of RJ423EV and RJ423200c cells. All tumors were collected when the RJ423EV tumors reached

A

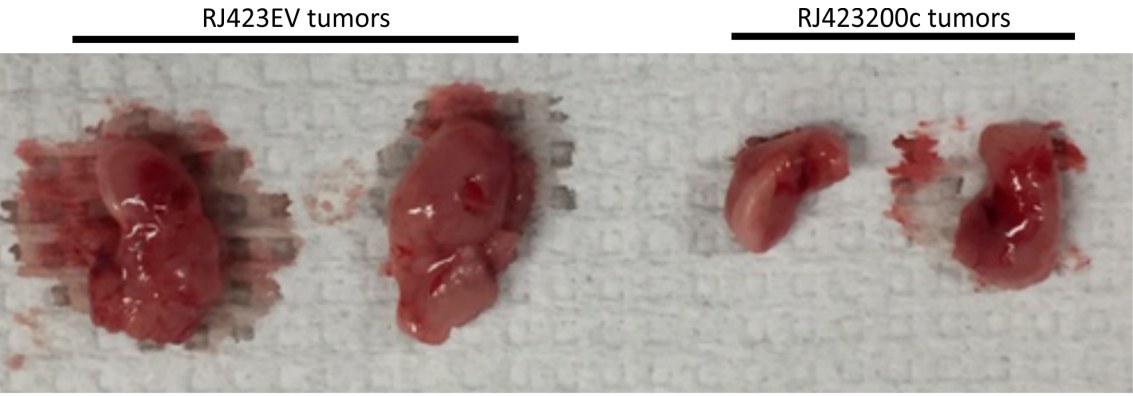

B

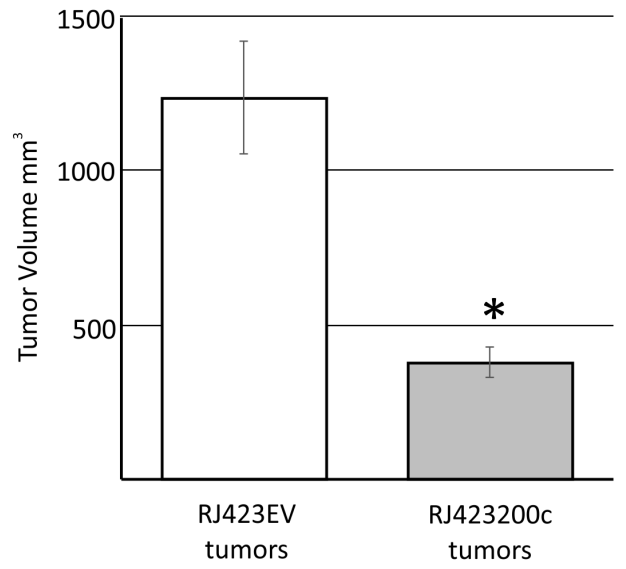

RJ423EV

RJ423200c
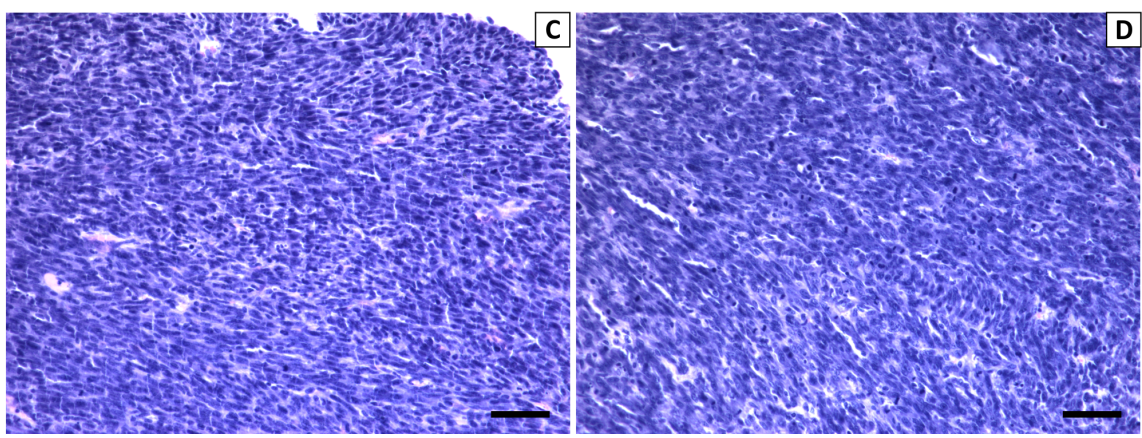

Figure 8: Representative macroscopic images of the mammary tumors that developed following the injection of RJ423EV or RJ423200c cells (A). Tumor volume (mean \pm SEM) was determined and was plotted as a bar graph $(\mathbf{B})$. * indicates significant difference $(\mathrm{p}<0.05)$. Panels $\mathrm{C}$ and $\mathrm{D}$ show representative hematoxylin and eosin stained sections of tumors induced following injection of RJ423EV (C) or RJ423200c (D) cells. Scale bars, 100 $\mu \mathrm{m}$. 
approximately $10 \%$ of the mouse's body weight which is the maximum tumor size allowed by the Canadian Council for Animal Care. As shown in Figure 8B, tumor volume was significantly lower in the mammary tumors induced by injection of RJ423200c cells compared to those produced by injection of RJ423EV cells (Figure 8B).

Tumors produced by the injection of either RJ423EV or RJ423200c cells had similar histologic features (Figure $8 \mathrm{C}, 8 \mathrm{D})$. The tumors were composed primarily of densely packed tumor cells with little stroma and frequently displayed regions of necrosis.

In an attempt to understand the mechanism of reduced tumor growth induced by miR-200c, proliferation, apoptosis and blood vessel density were assessed. To identify proliferating tumor cells, Ki67 immunohistochemistry was performed. Analysis of the Ki67 stained sections revealed that proliferating tumor cells were not evenly distributed throughout the tumor and cells undergoing anaphase were not stained by Ki67 (Figure 9A; Ki67 expression decreases during anaphase and telophase [48, 49]). Thus, in an attempt to accurately capture tumor cell proliferation rate, 5 sections of each tumor were randomly selected and the number of Ki-67
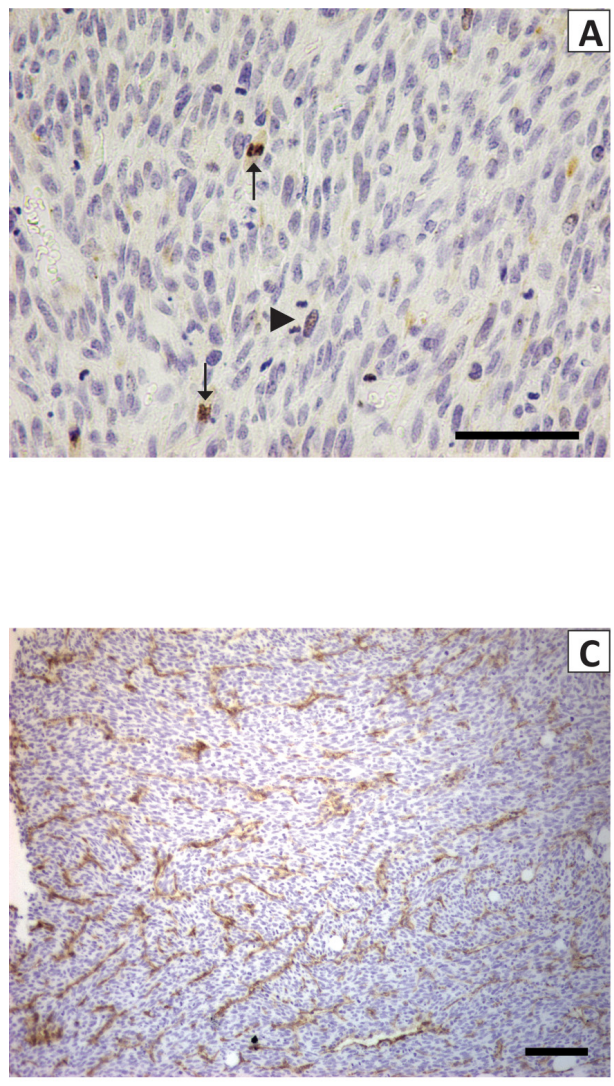

positive and anaphase cells were counted in a blinded manner (Figure 9A). The number of proliferating cells were then averaged across the 5 fields and we found that there was a non-significant ( $\mathrm{p}=0.089), 1.8$-fold decrease in tumor cell proliferation in RJ423200c tumors compared to RJ423EV tumors (Figure 9B).

Cleaved caspase-3 immunohistochemistry was performed to evaluate tumor apoptosis. However, a number of the tumors contained large regions of apparent necrosis and these regions stained strongly for cleaved caspase 3 (data not shown). These regions of staining made it impossible to accurately compare apoptosis between RJ423EV and RJ423200c tumors.

During tumor collection it was observed that mammary tumors induced by RJ423200c cells appeared to have fewer visible blood vessels compared to mammary tumors induced by RJ423EV cells. Therefore, blood vessel density was evaluated using CD31 immunohistochemistry. CD31 staining was variable in both RJ423200c and RJ423EV tumors with higher levels typically observed near the tumor periphery compared to the interior regions of the tumor. In an attempt to accurately determine whether differences in CD31 staining existed between RJ423EV

B
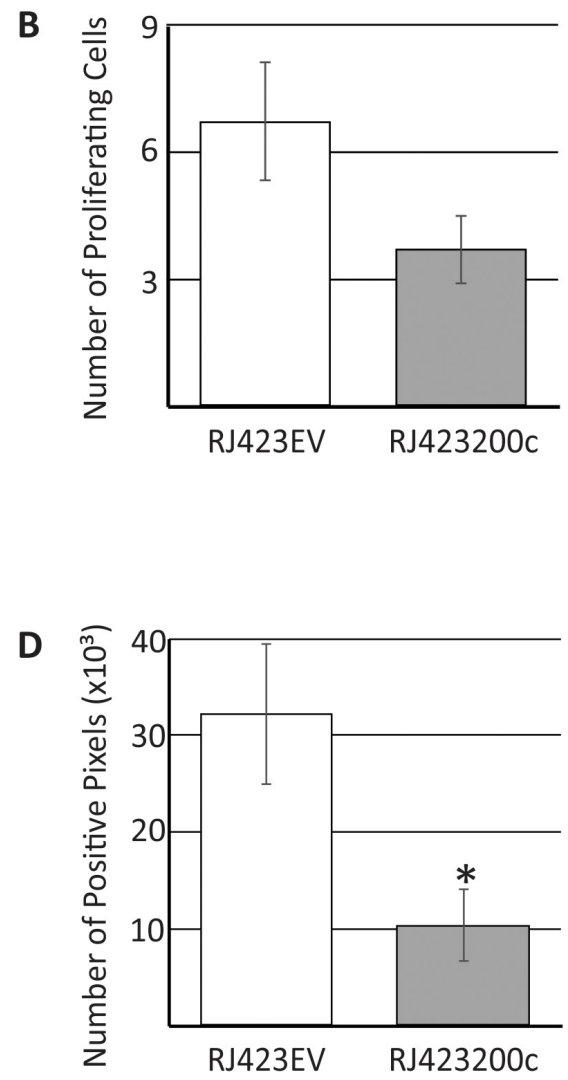

Figure 9: Representative section of a tumor stained with anti-Ki67 (A) or anti-CD31 (C). Arrows in panel (A) indicate positive staining for Ki67 while the arrowhead indicates a mitotic cell that did not stain with the anti-Ki67 antibody. Ki67 and CD31 staining were quantified and this data is shown in panels (B) and (D), respectively. Each bar represents the mean \pm SEM of 3 independent trials, ${ }^{*} p<0.05$. Scale bars, $100 \mu \mathrm{m}$. 
and RJ423200c tumors, four images were captured for each tumor; two areas of highest CD31 staining and two areas of lowest CD31 staining. The amount of CD31 staining was quantified using ImageScope positive pixel count v9.1 software (Aperio Technologies Inc, Vista, CA) and the average staining for the 4 images from each tumor was determined. As shown in Figure 9C, 9D the amount of CD31 staining was significantly higher in the tumors produced by RJ423EV cells compared to tumors produced by RJ423200c cells.

\section{DISCUSSION}

Our previous work demonstrated that mammary tumors induced by overexpression of IGF-IR in MTBIGFIR transgenic mice, also know as primary mammary tumors or PMTs, had features of luminal tumors such as an epithelial morphology and E-cadherin expression, however, these tumors clustered most closely with human basal-like breast tumors [39]. PMTs do not express the estrogen receptor (ER), as determined by immunohistochemistry, and this likely reduces the similarity of their gene expression profile to human luminal tumors which express ER and have high levels of ER regulated genes. In contrast, recurrent spindle tumors or RSTs develop in a subset of mice following downregulation of the IGF-IR. RSTs have gene expression patterns similar to human claudin-low breast cancers [39]. Claudin-low breast cancer is a relatively rare breast cancer subtype where the tumor cells possess mesenchymal characteristics as well as very low levels of claudin-3 (Cldn3), Cldn4 and Cdln7; properties that were observed in the RSTs [31, 32]. At least 2 new classification systems have been described for breast cancer and neither of these systems utilize the term claudin-low. In the classification system proposed by Lehmann et al [34], RSTs would be classified as mesenchymal stem-like tumors and in the system proposed by Jézéquel et al [35] RSTs would be classified as basal-enriched with high immune response and low M2 macrophage subtype. To be consistent with our previous publications the term claudin-low has been used in this study to describe tumors and cell lines derived from MTB-IGFIR mice that possess a mesenchymal morphology and express high levels of mesenchymal genes and low levels of E-cadherin and claudins-3, -4, -7.

A miRNA array was utilized to investigate miRNAs differentially expressed in PMTs compared to RSTs. A number of miRNAs were identified including the miR200f where all 5 members of this miRNA family were expressed at significantly lower levels in RSTs compared to PMTs. Reduced miR-200f expression in mesenchymal mammary tumors is consistent with studies published by Castilla et al [50] who demonstrated that luminal breast cancer had the highest level of miR-200f while mesenchymal breast cancers such as metaplastic breast cancer expressed only very low levels of miR-200f and
Herschowitz et al [51] who demonstrated that murine mammary tumors with features of claudin-low breast cancer presented with the lowest expression of miR-200f when compared to murine mammary tumors with features of other breast cancer subtypes. Moreover, a number of studies have demonstrated that one of the main functions of the miR-200f is to maintain cells in an epithelial state, at least in part, through the regulation of mesenchymal genes such as Snai1, Snai2, Twist1, Twist2, Zeb1 and Zeb2 (reviewed in [23, 24, 52-61]). Consistent with the low levels of the miR-200f in RSTs, these tumors express high levels of mesenchymal genes.

As it is difficult to manipulate miRNAs in transgenic mice, cell lines were derived from PMTs and RSTs and it was shown that these cell lines maintain gene and miRNA expression patterns similar to the tumors from which they were derived. RJ345 cells were derived from a PMT and these cells maintain an epithelial morphology in culture, express $C d h 1$ and only low levels of mesenchymal genes. RJ348 and RJ423 cells were derived from two different RSTs and both of these lines possess a mesenchymal morphology in culture, only express very low levels of Cdh1 but express higher levels of mesenchymal genes than the RJ345 cells. In addition, RJ345 cells express significantly higher levels of all members of the miR-200f compared to RJ348 and RJ423 cells.

In order to evaluate the function of the miR-200f in mesenchymal mammary tumor cells, miR-200c was reexpressed in RJ423 cells. This study focused on miR-200c as it was easier to manipulate a single miRNA rather than one or both miR-200f clusters and regulating an individual miRNA would simplify the analysis as each miRNA can potentially regulate hundreds or even thousands of mRNAs. Our study focused on the RJ423 cells as these cells are easier to stably transfect than the RJ348 cells.

Using a plasmid containing mmu-miR-200c driven by a CMV promoter, mature miR-200c levels could be restored nearly to the level observed in RJ345 cells and $>300$-fold higher than RJ423 cells transfected with an empty vector (RJ423EV cells). The expression of the other miR-200f members was not affected by transfection with the CMV-miR200c plasmid. Re-expression of miR-200c in RJ423 cells significantly reduced cell proliferation in vitro, however, the proliferation rate was not restored to the levels observed in RJ345 cells. Our findings are consistent with the study by Song et al [62] who demonstrated that miR-200c can suppress mammary tumor cell proliferation.

A number of studies have shown that miR-200f members negatively regulate cell migration and/or invasion [63-74] and we found that RJ423EV cells, which have very low miR-200f expression and high Zeb1/Zeb2 expression, were more invasive that RJ345 cells which have low Zeb1/Zeb2 expression and high miR$200 \mathrm{f}$ expression. However, re-expression of miR-200c in RJ423 cells did not significantly alter cell invasion. The lack of change in invasive properties following miR-200c 
re-expression in our study could be due to the modest changes in several of the mesenchymal genes such as Zeb1 and Zeb2 that have also been implicated in regulating cell migration and invasion [75-79]. Neither Zeb1 nor Zeb2 were significantly reduced by the re-expression of miR-200c in RJ423 cells. It should however be noted that one recent manuscript reported that re-expressed the miR-141/200c cluster in the human claudin-low breast cancer cell line, MDA-MB-231, found that miR-141/200c re-expression was associated with increased migration [80]. Therefore, it remains unclear whether miR-200f members universally inhibit tumor cell migration and/or invasion in all cell lines or whether the levels of miR-200f expression, the cell lines used, or the conditions employed can influence whether miR-200f can inhibit or stimulate migration and invasion.

Cell morphology displayed by RJ423EV and RJ423200c cells grown as monolayers was similar suggesting the re-expressing only miR-200c was insufficient to convert the mesenchymal RJ423 cells to epithelial cells. Re-expression of miR-200c did however induce a partial reversion of sphere morphology when the cells were grown as three dimensional cultures in matrigel. RJ423EV cells produced very loosely packed spheres similar to those observed for MDA-MB-231, a human claudin-low cell line while RJ345 cells produced tightly packed spheres similar to human luminal breast cancer cell lines [81]. RJ423200c spheres appeared to be densely packed but did not have the same clearly demarcated borders observed in RJ345 spheres.

One property that was completely restored was the inability to grow in soft agar. RJ423EV cells were capable of forming colonies under anchorage independent conditions while RJ345 cell very rarely formed colonies and RJ423200c failed to form colonies under these conditions. Although anchorage independent growth is only one characteristic of stem/progenitor cells, this finding is consistent with studies demonstrating that miR-200f members, including miR-200c can negatively influence cancer stem cell function $[17,18,25,65,82$, 83]. One specific example is a study by Shimono et al [18] that compared miRNA profiles between breast cancer stem cells and the remaining non-tumorigenic, breast cancer cells and 3 miRNA clusters, miR-200c/141, miR200b/200a/429 and miR-183/96/182, were consistently downregulated in breast cancer stem cells [18]. These 3 miRNA clusters were also found to be downregulated in normal mouse mammary stem/progenitor cells [18]. In addition, re-expression of miR-200c into MMTV-Wnt-1 induced murine mammary tumor cells almost completely suppressed colony formation and re-expression of miR200c in human breast cancer stem cells almost completely inhibited in vivo tumor growth in NOD/SCID mice [18, 82]. Therefore, our study and others suggest that miR$200 \mathrm{c}$ can inhibit progenitor/stem cell function in mammary tumor cells.
Other potential contributors of reduced in vivo tumor growth were the observed 1.8-fold decrease in tumor cell proliferation (although this difference did not reach statistical significance; $p=0.089$ ) and a significant decrease in CD31 staining. CD31 is a transmembrane glycoprotein found in endothelial cells, that is used to detect tumor vasculature [84-86]. Interestingly, one of the genes regulated by miR-200c and found to be significantly downregulated in RJ42300c cells was Flt1 [87]. FLT1 also known as VEGFR1 (vascular endothelial growth factor receptor 1) is a tyrosine kinase receptor that binds VEGF-A, VEGF-B and placental growth factor (PLGF) and regulates angiogenesis in normal tissues as well as tumors (reviewed in [88, 89]). However, FLT1 traditionally regulates angiogenesis through it's function in endothelial cells, not tumor cells, so it remains unclear how tumor cell Flt1 expression could influence tumor vascularity. Flt1 expression has been found in tumor cells including breast cancer cells [90, 91] where FLT1 functions as a tumor growth regulator and pro-survival factor. Other members of the $V e g f$ family were evaluated in our RNA sequencing data and only $\operatorname{Veg} f c$ was significantly downregulated in RJ423200c cells compared to RJ423EV cells. Although iPathwayGuide did not identify $V e g f c$ as a miR-200c target, Vegfc does contain a predicted miR-200c binding site (microRNA.org) and thus can potentially be regulated by miR-200c expression. Therefore, decreased Flt1 expression in the RJ423200c cells may suppress proliferation and reduced $V e g f c$ expression in RJ423200c cells could restrict angiogenesis, both of which could contribute to the observed reduction in tumor growth. Inhibition of angiogenesis by miR-200c is consistent with a study by Pecot et al [92] that showed miR-200 family members could regulate tumor angiogenesis in basal-like breast cancer.

Other miR-200c targets identified by RNA sequencing included Arhgap6, Dmd, Slc14a1, and Vldlr. Dmd and Vldlr have previously been identified as regulators of breast cancer where their expression has been associated with paclitaxel or bevacizumab response $[93,94]$ and migration/metastasis [95]. Arhgap6 and Slc14al have not been implicated in breast cancer but have been implicated in a number of other cancers including cervical, endometrial, prostate and bladder cancer [96-100]. Interestingly, bevacizumab, an antibody that inhibits VEGFA function and thus angiogenesis, altered the expression of Vldlr in basal-like breast cancer [93] and Arhgap6 in endometrial cancer [97]. Therefore, Vldlr and Arhgap6 may also impact tumor angiogenesis in our model.

In summary, re-expression of miR-200c in murine claudin-low mammary tumor cells reduces proliferation and colony formation in vitro and tumor growth in vivo. Thus, our work further demonstrates the importance of restoring miR-200c expression as a mechanism to inhibit the growth/tumorigenic potential of claudin-low mammary tumor cells. 


\section{MATERIALS AND METHODS}

\section{miRNA Array}

One hundred micrograms of total RNA from each sample was sent to the University Health Network Microarray Centre, Toronto, ON, Canada and RNA quality check, labeling, hybridization and scanning were performed by the University Health Network Microarray Centre. RNA quality was checked using an Agilent Bioanalyzer (Agilent Technologies, Santa Clara, CA) and all samples had a RIN $>7$. RNA was then labelled and hybridized using Agilent miRNA labeling and hybridization kits following the manufacturer's protocols and miRNA expression was determined using an Agilent 8x15K v2:627 mouse miRNA array (Agilent Technologies, Santa Clara, CA). Slides were scanned on a G2565C scanner (Agilent Technologies, Santa Clara, CA) and values were generated using feature extraction software version 10.5 and the extraction protocol miRNA_105 Dec08. Fold changes in miRNAs was determined using Genespring 12 (Agilent Technologies, Santa Clara, CA).

\section{RNA extraction, taqman qRT-PCR for microRNA expression and $q R T-P C R$ for gene expression}

RNA was extracted using a mirVana miRNA Isolation kit (Thermo Fisher Scientific, Burlington, ON). For the analysis of miRNA expression, the TaqMan microRNA reverse transcription kit (Thermo Fisher Scientific, Burlington, ON) was use to reverse transcript $100 \mathrm{ng}$ of total RNA into cDNA following the manufacturer's protocol. Briefly, 100 ng of RNA (in 5 $\mu \mathrm{l})$ was mixed with $0.15 \mu \mathrm{l}$ of dNTP $\operatorname{mix}(100 \mathrm{mM}$ total), $1 \mu \mathrm{l}$ multiscribe RT enzyme $(50 \mathrm{U} / \mu \mathrm{l}), 1.5 \mu \mathrm{l}$ of $10 \mathrm{xRT}$ buffer, $0.19 \mu \mathrm{l}$ of RNase inhibitor $(20 \mathrm{U} / \mu \mathrm{l}), 4.16 \mu \mathrm{l}$ of nuclease-free water and $3 \mu \mathrm{l}$ of $5 \mathrm{x}$ miRNA primer. Reverse transcription was performed on a thermal cycler with samples incubated at $16^{\circ} \mathrm{C}$ for $30 \mathrm{~min}, 42^{\circ} \mathrm{C}$ for $30 \mathrm{~min}$, $85^{\circ} \mathrm{C}$ for $5 \mathrm{~min}$ and then held at $4^{\circ} \mathrm{C}$ until used for qPCR. Primers for reverse transcribing (5x primers) and for amplifying cDNA (20x primers) for miR-141 (ID 000463), miR-200a (ID 000502), miR-200b (ID 001800), miR-200c (ID 002300), miR-429, SnoRNA202 (ID 001232) and SnoRNA234 (ID 001234) were obtained from Thermo Fisher Scientific (Burlington, ON). qPCR was performed a CFX96 real-time PCR machine (Bio-Rad Laboratories, Mississauga, ON) using $2 \mu \mathrm{l}$ of each cDNA reaction, $10 \mathrm{ul}$ of TaqMan universal master mix II no UNG (Thermo Fisher Scientific, Burlington, ON) $1 \mu 1$ of $20 x$ primer and $7 \mu l$ of water and the following incubation conditions; $50^{\circ} \mathrm{C}$ for $2 \mathrm{~min}, 95^{\circ} \mathrm{C}$ for $10 \mathrm{~min}$ and then 40 cycles of $95^{\circ} \mathrm{C}$ for $15 \mathrm{~s}$ and $60^{\circ} \mathrm{C}$ for $1 \mathrm{~min}$. miRNA levels were calculated using Bio-Rad CFX Manager 3.1 (Bio-Rad Laboratories,
Mississauga, ON) and were normalized to the levels of SnoRNA202 and SnoRNA234.

For the analysis of gene expression, 1 ug of total RNA was reverse transcribed using $4 \mathrm{ul}$ of qScript cDNA supermix (Quanta Biosciences, Beverly, MA) per 20 $\mu \mathrm{l}$ reaction and the following incubation conditions on a thermal cycler; $25^{\circ} \mathrm{C}$ for $5 \mathrm{~min}, 42^{\circ} \mathrm{C}$ for $30 \mathrm{~min}, 85^{\circ} \mathrm{C}$ for $5 \mathrm{~min}$ and then held at $4^{\circ} \mathrm{C}$ until used for qPCR. For qPCR, $1 \mu \mathrm{l}$ of cDNA was mixed with $10 \mu \mathrm{l}$ of SsoFast EvaGreen supermix (Bio-Rad Laboratories, Mississauga, ON) and $9 \mu \mathrm{l}$ of water and gene expression was quantified using a CFX96 real-time PCR machine (Bio-Rad Laboratories, Mississauga, $\mathrm{ON}$ ) and the following program; $95^{\circ} \mathrm{C}$ for $2 \mathrm{~min}$ and then 40 cycles of $95^{\circ} \mathrm{C}$ for $5 \mathrm{~s}$ and $60^{\circ} \mathrm{C}$ for $30 \mathrm{~s}$. All gene primers were obtained from Bio-Rad Laboratories (Mississauga, ON); Arhgap6 (aMmuCID0009097), Cdh1 (qMmuCID0005843), Cldn3 (qMmuCED0001019), Cldn4 (qMmuCED0003218), Cldn7 (qMmuCED0005006), Dmd (qMmuCID0018306), Flt1 (qMmuCID0016762), Hprt (qMmuCED0045738), Slc14al (qMmuCID0017253), Twist1 (qMmuCED0004065), Twist2 (qMmuCID0009652) Vim (qMmuCID0005527), Vldlr (aMmuCID0011365), Zeb1 (qMmuCID0009095), and Zeb2 (qMmuCID0014662). Gene expression was quantified using Bio-Rad CFX Manager 3.1 (Bio-Rad Laboratories, Mississauga, ON) and were normalized to the levels of Hprt.

\section{miR-200c promoter methylation analysis}

Two approaches were utilized to determine methylation of the miR-200c promoter. In the first approach, DNA isolated from RJ345, RJ423 and RJ348 cells using a Quick-DNA Universal Kit (Cedarlane, Burlington, ON) or DNA isolated from primary mammary tumors (PMTs) or recurrent spindle tumors (RSTs), described in [41], using DNeasy Blood and Tissue Kit (Qiagen, Germantown, MD) was sent to Zymo Research Corporation for targeted bisulfite sequencing of the miR$200 \mathrm{c} / 141$ promoter region. DNA samples sent to Zymo Research were bisulfite converted and relevant regions were PCR amplified using 6 sets of primers covering 33 CpG site in the first 1000bp upstream of the miR-200c/141 cluster. The PCR amplified DNA was then sequenced. A CpG methylation ratio was calculated by determining the number reads of methylated $\mathrm{CpG}$ sites relative to the total $\mathrm{CpG}$ read counts. Only $\mathrm{CpG}$ sites with at least 10 reads were evaluated and this meant that $30 \mathrm{CpG}$ sites were evaluated.

In the second approach, RJ423 cells were treated with $3 \mu \mathrm{M}$ of 5 -aza-2'-deoxycytidine daily for 72 hours or the equivalent amount of DMSO daily for 72 hours. At the end of the treatment period, RNA was extracted and Taqman qRT-PCR for miR-200c or miR-200b (first member of each cluster) was performed as described above using SnoRNA202 and SnoRNA234 as normalizers. 


\section{Expression plasmids and generation of stable cell lines}

The microRNA expression plasmid containing murine miR-200c was purchased from Origene (cat \# SC400903; Origene Technologies, Rockville, MD). In this plasmid, mmu-miR-200c expression is driven by a CMV promoter. RJ423200c cells were created by transfecting RJ423 cells with $1 \mu \mathrm{g}$ of the pCMV-miR-200c plasmid using $5 \mu \mathrm{l} / \mathrm{ml}$ of Lipofectamine 2000 (Thermo Fisher Scientific, Burlington, ON). The same conditions were used to transfect RJ423 cells with the empty vector control (cat\# PCMVMIR; Origene Technologies, Rockville, MD). Cells were cultured in the presence of $1 \mathrm{mg} / \mathrm{ml}$ Geneticin (Thermo Fisher Scientific, Burlington, ON; this concentration was sufficient to kill untransfected, parental cells).

\section{Immunofluorescence}

Cell proliferation was determined using immunofluorescence for phospho-histone $\mathrm{H} 3$ while apoptosis was determined using immunofluorescence for cleaved caspase $3.1 \times 10^{5}$ of 345 , RJ423EV or RJ423200c cells were each plated in fully supplemented media on sterile glass coverslips in a 6-well plate. The next day, cells were washed in PBS and fixed in 10\% neutral buffered formalin for 1 hour at room temperature. The cells were then washed again with PBS and permeabilized with $0.2 \%$ Triton X-100 in PBS solution for 5 minutes. Cells were then blocked using 5\% BSA, 0.1\% Triton X-100 in PBS for 10 minutes. Coverslips were incubated with either a 1:2,000 dilution of anti-phospho histone H3 (Abcam Inc, Toronto, ON cat\#ab14955) or a 1:500 dilution of anti-cleaved caspase 3 (Cell Signaling Technology, MA cat\#ab9661) overnight at $4^{\circ} \mathrm{C}$. The coverslips were then incubated with a 1:500 dilution of goat anti-mouse Alexa Fluor 488 secondary antibody (Thermo Fisher Scientific, Burlington, ON cat\#A-11001) at room temperature for 1 hour. Cell nuclei were counterstained with DAPI and mounted using Prolong Gold (Thermo Fisher Scientific, Burlington, ON). Images were taken using MetaMorph Imaging Software (Molecular Devices, Sunnyvale, CA) on an Olympus BX961 fluorescent signal microscope (Olympus, Center Valley, PA). The percentage of cells positive for phospho-histone $\mathrm{H} 3$ or cleaved caspase 3 was determined by manual counting using the ImageJ software (National Institutes of Health, Bethesda, MD). Experiments were performed in triplicate $(n=3)$.

\section{Immunohistochemistry}

To detect blood vessels, immunohistochemistry was performed as previously described [101] using a 1:100 dilution of anti-CD31 (cat \#77699; Cell Signaling, Danvers, MA) in 5\% goat serum in tris-buffered saline containing $0.1 \%$ Tween 20 . Images were captured on a
Nikon E600 microscope (Nikon Instruments Inc, Melville, NY). For each tumor, two regions of the highest levels of CD31 staining and two regions of the lowest levels of CD31 staining were captured and the amount of staining was quantified using the positive pixel count $\mathrm{v} 9$ algorithm in ImageScope software (Aperio Technologies, Vista, CA) and the average staining per tumor was determined.

To detect the number of proliferating tumor cells, immunohistochemistry was performed as previously described [101] using a 1:200 dilution of Ki67 (cat\#12202; Cell Signaling, Danvers, MA) in 5\% goat serum in trisbuffered saline containing $0.1 \%$ Tween 20 . Each tumor section was analyzed in a blinded manner and 5 fields were randomly selected. In each field, the number of Ki67 positive cells and the number of mitotic figures were counted and the number counted in the 5 fields were averaged to obtain the number of proliferating cells/field/ tumor.

\section{Invasion chamber assay}

Invasion chamber inserts from BioCoat Matrigel Invasion Chamber kit (Corning, NY) were used. The inserts were thawed and rehydrated in a 24 well plate using serum free media both beneath and inside the insert for 2 hours. The inserts were placed on top of $750 \mu$ of serum containing media in a new well of the 24 well plate. $5 \times 10^{4}$ of RJ345, RJ423EV, or RJ423200c cells were each seeded in serum free media on top of the inserts. After 24 hours, cells that had migrated to the opposite sided of the chamber were fixed in $100 \%$ methanol for 2 minutes at room temperature and then stained with toluidine blue for 2 minutes at room temperature. Cells were imaged using an inverted Olympus IX71 microscope with Q Imaging software (Q Imaging). The number of cells able to migrate and invade through the insert were counted manually using the ImageJ software (National Institutes of Health). Experiments were performed in triplicate $(n=3)$.

\section{Soft agar assay}

A $4 \mathrm{~mL}$ layer of $1: 1,1.5 \%$ agar and $2 \mathrm{X}$ media was placed in a $60 \mathrm{ml}$ dish and allowed to solidify for 30 minutes to prevent the attachment of cells to the bottom of the dish. After the agar had solidified $2 \times 10^{4}$ of RJ345, RJ423EV, or RJ423200c cells were seeded in a 1:1 mixture of $2 \mathrm{X}$ media and $0.75 \%$ agar solution on top of the base agar layer in the $60 \mathrm{ml}$ dish. At least 3 plates were seeded for each cell line and the experiment was repeated on three different days. Media was added twice weekly for 30 days. After 30 days, individual colonies were manually counted.

\section{D Culture in matrigel}

Cell lines were seeded in 150 ul of growth media supplemented with 5\% growth-factor reduced Matrigel ${ }^{\circledR}$ (Thermo Fisher Scientific, Burlington, ON) at a density 
of 500 cells per well in 96-well low attachment plates (Thermo Fisher Scientific, Burlington, ON). Cells were cultured up to 7 days without further media changes. Images were acquired using the EVOS Cell Imaging System (Thermo Fisher Scientific, Burlington, ON).

\section{RNA sequencing}

RNA sequencing and analysis was performed on RNA extracted from RJ423EV and RJ423200c cells at the Genome Quebec Innovation Centre at McGill University using the Illumina Hiseq 2500 v4 PE125. Reads were trimmed using Trimmomatic software [102] from the 3 ' end to have a phred score of at least 30 . Sequencing adapters were removed from the reads and only reads of at least 32 base pairs were used. Filtered reads were aligned to the Mus_musculus assembly GRCm38 reference genome using STAR [103]. RNA-seq reads were aligned to genes and their abundance estimated using Cufflinks [104]. Differential gene expression analysis was performed using DESeq [105] and edgeR [106] R Bioconductor packages. RNA Sequencing data was further analyzed with iPathwayGuide software (Advaita Corporation, Plymouth, MI) using genes with at least 2-fold difference in expression and a minimum Deseq adjusted p-value of 0.01 . For pathway analysis in iPathwayGuide, FDR correction was used.

\section{Intra-mammary tumor cell injection}

Tumor cells were injected into the mammary glands of wild type, syngeneic, FVB mice as described in [107] using $5 \times 10^{4}$ or $5 \times 10^{5}$ cells. All mice were monitored 2 times per week by palpating the mammary glands. Once a palpable mammary tumor was identified tumor size was measured using digital calipers. Once the RJ423EV tumors reached $\sim 10 \%$ of the mouse's body weight, the mice bearing RJ423EV or RJ423200c tumors were euthanized and the mammary tumors collected. Each mammary tumor was divided for fixation in formalin, cryopreservation in OCT and flash frozen in liquid nitrogen. Animals were housed and cared for following guidelines established by the Central Animal Facility at the University of Guelph and the guidelines established by the Canadian Council of Animal Care. This study was approved by the Animal Care Committee at the University of Guelph.

\section{Statistics}

For analysis comparing the means of two different groups, a Student's t-test was performed. For analyses comparing the means of three or more groups, an ANOVA followed by a Tukey's test was performed. In both cases, means were considered statistically different when $\mathrm{p}<0.05$.

\section{Abbreviations}

Arhgap6: Rho GTPase activating protein 6, CD31: platelet and endothelial cell adhesion molecule 1, Cdh1: E-cadherin, Cldn: claudin, CMV: cytomegalovirus, Dmd: dystrophin, EMT: epithelial-to-mesenchymal transition, ER: estrogen receptor, Flt1: Fms related tyrosine kinase 1, HER2: human epidermal growth factor receptor 2, Hprt: hypoxanthine phosphoribosyltranferase 1, IGFIR: type I insulin-like growth factor receptor, Ki67: marker of proliferation KI-67, miR: microRNA, miR200f: miRNA-200 family, MTB-IGFIR: transgenic mice expressing IGF-IR in mammary epithelial cells, nt: nucleotide, PMT: primary mammary tumor, PR: progesterone receptor, RISC: RNA-induced silencing complex, RST: recurrent spindle tumor, S100a4: S100 calcium binding protein 4, Slc14a1: solute carrier family 14 member 1 (Kidd blood group), Snai1: snail family transcriptional repressor 1, Snai2: snail family transcriptional repressor 2, Twist1: twist family BHLH transcription factor 1, Twist2: twist family BHLH transcription factor 2, UTR: untranslated region, Vegfc: vascular endothelial growth factor c, Vim: vimentin, Vldlr: very low density lipoprotein receptor, Zeb1: zinc finger E-box binding homeobox 1, Zeb2: zinc finger E-box binding homeobox 2 .

\section{CONFLICTS OF INTEREST}

All authors confirm that there are no conflicts of interest.

\section{FUNDING}

This work was funded by a CIHR operating grant MOP-136970 awarded to RAM.

\section{Author contributions}

RAJ performed the matrigel assays, some of the immunohistochemistry and immunofluorescence assays and extracted RNA for the miRNA array. KLW performed some of the immunohistochemistry and immunofluorescence assays, performed the intramammary tumor cell injections, monitored the tumor bearing mice, collected the tumors and performed some of the invasion chamber assays. AB created the RJ423EV and RJ423200c cell lines and assisted with the in vivo experiments and assisted with the experiment evaluating miR-200f levels. SN performed the soft agar assays and some of the invasion chamber assays. JK performed some of the RT-PCR evaluating miR-200f expression levels. RAM ran the project, wrote the manuscript, extracted DNA for miR-200c promoter methylation analysis, analyzed the RNA sequencing data and performed the gene expression analysis using RT-PCR. 


\section{REFERENCES}

1. Hutvagner G, McLachlan J, Pasquinelli AE, Balint E, Tuschl T, Zamore PD. A cellular function for the RNAinterference enzyme Dicer in the maturation of the let-7 small temporal RNA. Science. 2001; 293:834-838.

2. Grishok A, Pasquinelli AE, Conte D, Li N, Parrish S, Ha I, Baillie DL, Fire A, Ruvkun G, Mello CC. Genes and mechanisms related to RNA interference regulate expression of the small temporal RNAs that control C. elegans developmental timing. Cell. 2001; 106:23-34.

3. Lee RC, Feinbaum RL, Ambros V. The C. elegans heterochronic gene lin-4 encodes small RNAs with antisense complementarity to lin-14. Cell. 1993; $75: 843-854$

4. Wightman B, Ha I, Ruvkun G. Posttranscriptional regulation of the heterochronic gene lin-14 by lin- 4 mediates temporal pattern formation in C. elegans. Cell. 1993; 75:855-862.

5. Di LG, Calin GA, Croce CM. MicroRNAs: fundamental facts and involvement in human diseases. Birth Defects ResCEmbryoToday. 2006; 78:180-189.

6. Kim VN, Nam JW. Genomics of microRNA. Trends Genet. 2006; 22:165-173.

7. Bartel DP. MicroRNAs: genomics, biogenesis, mechanism, and function. Cell. 2004; 116:281-297.

8. Czech B, Hannon GJ. Small RNA sorting: matchmaking for Argonautes. NatRevGenet. 2011; 12:19-31.

9. Chendrimada TP, Gregory RI, Kumaraswamy E, Norman J, Cooch N, Nishikura K, Shiekhattar R. TRBP recruits the Dicer complex to Ago2 for microRNA processing and gene silencing. Nature. 2005; 436:740-744.

10. Hock J, Meister G. The Argonaute protein family. Genome Biol. 2008; 9:210.

11. Filipowicz W, Bhattacharyya SN, Sonenberg N. Mechanisms of post-transcriptional regulation by microRNAs: are the answers in sight? NatRevGenet. 2008; 9:102-114

12. Croce CM. Causes and consequences of microRNA dysregulation in cancer. NatRevGenet. 2009; 10:704-714.

13. Humphries B, Yang C. The microRNA-200 family: small molecules with novel roles in cancer development, progression and therapy. Oncotarget. 2015; 6:6472-6498. doi: 10.18632/oncotarget.3052.

14. Nana-Sinkam SP, Croce CM. MicroRNAs as therapeutic targets in cancer. TranslRes. 2011; 157:216-225.

15. Saini HK, Enright AJ, Griffiths-Jones S. Annotation of mammalian primary microRNAs. BMC genomics. 2008; 9:564.

16. Trumbach D, Prakash N. The conserved miR-8/miR-200 microRNA family and their role in invertebrate and vertebrate neurogenesis. Cell Tissue Res. 2015; 359:161-177.

17. Lim YY, Wright JA, Attema JL, Gregory PA, Bert AG, Smith E, Thomas D, Lopez AF, Drew PA, Khew-Goodall Y,
Goodall GJ. Epigenetic modulation of the miR-200 family is associated with transition to a breast cancer stem-cell-like state. J Cell Sci. 2013; 126:2256-2266.

18. Shimono Y, Zabala M, Cho RW, Lobo N, Dalerba P, Qian D, Diehn M, Liu H, Panula SP, Chiao E, Dirbas FM, Somlo G, Pera RA, et al. Downregulation of miRNA-200c links breast cancer stem cells with normal stem cells. Cell. 2009; 138:592-603.

19. Wellner U, Schubert J, Burk UC, Schmalhofer O, Zhu F, Sonntag A, Waldvogel B, Vannier C, Darling D, zur Hausen A, Brunton VG, Morton J, Sansom O, et al. The EMTactivator ZEB1 promotes tumorigenicity by repressing stemness-inhibiting microRNAs. Nat Cell Biol. 2009; 11:1487-1495.

20. Gill JG, Langer EM, Lindsley RC, Cai M, Murphy TL, Kyba M, Murphy KM. Snail and the microRNA-200 family act in opposition to regulate epithelial-to-mesenchymal transition and germ layer fate restriction in differentiating ESCs. Stem Cells. 2011; 29:764-776.

21. Wang G, Guo X, Hong W, Liu Q, Wei T, Lu C, Gao L, Ye D, Zhou Y, Chen J, Wang J, Wu M, Liu H, Kang J. Critical regulation of miR-200/ZEB2 pathway in Oct4/Sox2induced mesenchymal-to-epithelial transition and induced pluripotent stem cell generation. Proc Natl Acad Sci U S A. 2013; 110:2858-2863.

22. Zhang B, Zhang Z, Xia S, Xing C, Ci X, Li X, Zhao R, Tian S, Ma G, Zhu Z, Fu L, Dong JT. KLF5 activates microRNA 200 transcription to maintain epithelial characteristics and prevent induced epithelial-mesenchymal transition in epithelial cells. Mol Cell Biol. 2013; 33:4919-4935.

23. Howe EN, Cochrane DR, Richer JK. The miR-200 and miR-221/222 microRNA families: opposing effects on epithelial identity. JMammaryGlandBiolNeoplasia. 2012; 17:65-77.

24. Hill L, Browne G, Tulchinsky E. ZEB/miR-200 feedback loop: At the crossroads of signal transduction in cancer. IntJCancer. 2012.

25. Radisky DC. miR-200c at the nexus of epithelialmesenchymal transition, resistance to apoptosis, and the breast cancer stem cell phenotype. Breast Cancer Res. 2011; 13:110.

26. Bracken CP, Gregory PA, Kolesnikoff N, Bert AG, Wang J, Shannon MF, Goodall GJ. A double-negative feedback loop between ZEB1-SIP1 and the microRNA-200 family regulates epithelial-mesenchymal transition. Cancer Res. 2008; 68:7846-7854.

27. Peinado H, Olmeda D, Cano A. Snail, Zeb and bHLH factors in tumour progression: an alliance against the epithelial phenotype? NatRevCancer. 2007; 7:415-428.

28. Yang J, Weinberg RA. Epithelial-mesenchymal transition: at the crossroads of development and tumor metastasis. DevCell. 2008; 14:818-829.

29. Bockmeyer CL, Christgen M, Muller M, Fischer S, Ahrens P, Langer F, Kreipe H, Lehmann U. MicroRNA profiles 
of healthy basal and luminal mammary epithelial cells are distinct and reflected in different breast cancer subtypes. Breast Cancer ResTreat. 2011; 130:735-745.

30. Cochrane DR, Cittelly DM, Howe EN, Spoelstra NS, McKinsey EL, LaPara K, Elias A, Yee D, Richer JK. MicroRNAs link estrogen receptor alpha status and Dicer levels in breast cancer. HormCancer. 2010; 1:306-319.

31. Prat A, Parker JS, Karginova O, Fan C, Livasy C, Herschkowitz JI, He X, Perou CM. Phenotypic and molecular characterization of the claudin-low intrinsic subtype of breast cancer. Breast Cancer Res. 2010; 12:R68.

32. Herschkowitz JI, Simin K, Weigman VJ, Mikaelian I, Usary J, Hu Z, Rasmussen KE, Jones LP, Assefnia S, Chandrasekharan S, Backlund MG, Yin Y, Khramtsov AI, et al. Identification of conserved gene expression features between murine mammary carcinoma models and human breast tumors. Genome Biol. 2007; 8:R76.

33. Anders CK, Abramson V, Tan T, Dent R. The Evolution of Triple-Negative Breast Cancer: From Biology to Novel Therapeutics. American Society of Clinical Oncology educational book/ASCO American Society of Clinical Oncology Meeting. 2016; 35:34-42.

34. Lehmann BD, Bauer JA, Chen X, Sanders ME, Chakravarthy AB, Shyr Y, Pietenpol JA. Identification of human triple-negative breast cancer subtypes and preclinical models for selection of targeted therapies. J Clin Invest. 2011; 121:2750-2767.

35. Jezequel P, Loussouarn D, Guerin-Charbonnel C, Campion L, Vanier A, Gouraud W, Lasla H, Guette C, Valo I, Verriele V, Campone M. Gene-expression molecular subtyping of triple-negative breast cancer tumours: importance of immune response. Breast Cancer Res. 2015; 17:43.

36. Saleh S, Thompson DE, McConkey J, Murray P, Moorehead RA. Osteopontin regulates proliferation, apoptosis, and migration of murine claudin-low mammary tumor cells. BMC cancer. 2016; 16:359.

37. Stalker L, Pemberton J, Moorehead RA. Inhibition of proliferation and migration of luminal and claudin-low breast cancer cells by PDGFR inhibitors. Cancer Cell Int. 2014; 14:89.

38. Thompson DE, Siwicky MD, Moorehead RA. Caveolin-1 expression is elevated in claudin-low mammary tumor cells. Cancer Cell Int. 2012; 12:6.

39. Franks SE, Campbell CI, Barnett EF, Siwicky MD, Livingstone J, Cory S, Moorehead RA. Transgenic IGF-IR overexpression induces mammary tumors with basal-like characteristics while IGF-IR independent mammary tumors express a claudin-low gene signature. Oncogene. 2012; 31:3298-3309.

40. Campbell CI, Thompson DE, Siwicky MD, Moorehead RA. Murine mammary tumor cells with a claudin-low genotype. Cancer Cell International. 2011; 11:28.
41. Jones RA, Campbell CI, Wood GA, Petrik JJ, Moorehead RA. Reversibility and recurrence of IGF-IR-induced mammary tumors. Oncogene. 2009; 13:407-413.

42. Jones RA, Campbell CI, Gunther EJ, Chodosh LA, Petrik JJ, Khokha R, Moorehead RA. Transgenic overexpression of IGF-IR disrupts mammary ductal morphogenesis and induces tumor formation. Oncogene. 2007; 26:1636-1644.

43. Campbell CI, Thompson DE, Siwicky MD, Moorehead RA. Murine mammary tumor cells with a claudin-low genotype. Cancer Cell Int. 2011; 11:28.

44. Vrba L, Jensen TJ, Garbe JC, Heimark RL, Cress AE, Dickinson S, Stampfer MR, Futscher BW. Role for DNA methylation in the regulation of miR-200c and miR-141 expression in normal and cancer cells. PloS one. 2010; 5:e8697.

45. Neves R, Scheel C, Weinhold S, Honisch E, Iwaniuk KM, Trompeter HI, Niederacher D, Wernet P, Santourlidis $\mathrm{S}$, Uhrberg $\mathrm{M}$. Role of DNA methylation in miR200c/141 cluster silencing in invasive breast cancer cells. BMCResNotes. 2010; 3:219.

46. Tuna M, Machado AS, Calin GA. Genetic and epigenetic alterations of microRNAs and implications for human cancers and other diseases. Genes Chromosomes Cancer. 2016; 55:193-214.

47. Damiano V, Brisotto G, Borgna S, di Gennaro A, Armellin M, Perin T, Guardascione M, Maestro R, Santarosa M. Epigenetic silencing of miR-200c in breast cancer is associated with aggressiveness and is modulated by ZEB1. Genes Chromosomes Cancer. 2017; 56:147-158.

48. Starborg M, Gell K, Brundell E, Hoog C. The murine Ki-67 cell proliferation antigen accumulates in the nucleolar and heterochromatic regions of interphase cells and at the periphery of the mitotic chromosomes in a process essential for cell cycle progression. J Cell Sci. 1996; 109:143-153.

49. Gerdes J, Lemke H, Baisch H, Wacker HH, Schwab U, Stein H. Cell cycle analysis of a cell proliferation-associated human nuclear antigen defined by the monoclonal antibody Ki-67. J Immunol. 1984; 133:1710-1715.

50. Castilla MA, Diaz-Martin J, Sarrio D, Romero-Perez L, Lopez-Garcia MA, Vieites B, Biscuola M, RamiroFuentes S, Isacke CM, Palacios J. MicroRNA-200 family modulation in distinct breast cancer phenotypes. PloS one. 2012; 7:e47709.

51. Herschkowitz JI, Zhao W, Zhang M, Usary J, Murrow G, Edwards D, Knezevic J, Greene SB, Darr D, Troester MA, Hilsenbeck SG, Medina D, Perou CM, et al. Comparative oncogenomics identifies breast tumors enriched in functional tumor-initiating cells. Proc Natl Acad Sci U S A. 2012; 109:2778-2783.

52. Zaravinos A. The Regulatory Role of MicroRNAs in EMT, Cancer. J Oncol. 2015; 2015:865816.

53. Diaz-Lopez A, Moreno-Bueno G, Cano A. Role of microRNA in epithelial to mesenchymal transition and 
metastasis and clinical perspectives. Cancer management and research. 2014; 6:205-216.

54. Guo F, Parker Kerrigan BC, Yang D, Hu L, Shmulevich I, Sood AK, Xue F, Zhang W. Post-transcriptional regulatory network of epithelial-to-mesenchymal and mesenchymalto-epithelial transitions. J Hematol Oncol. 2014; 7:19.

55. Guttilla IK, Adams BD, White BA. ERalpha, microRNAs, and the epithelial-mesenchymal transition in breast cancer. Trends Endocrinol Metab. 2012; 23:73-82.

56. Brabletz S, Brabletz T. The ZEB/miR-200 feedback loop--a motor of cellular plasticity in development and cancer? EMBO Rep. 2010; 11:670-677.

57. Mongroo PS, Rustgi AK. The role of the miR-200 family in epithelial-mesenchymal transition. Cancer biology \& therapy. 2010; 10:219-222.

58. Peter ME. Let-7 and miR-200 microRNAs: guardians against pluripotency and cancer progression. Cell Cycle. 2009; 8:843-852.

59. Korpal M, Kang Y. The emerging role of miR-200 family of microRNAs in epithelial-mesenchymal transition and cancer metastasis. RNA biology. 2008; 5:115-119.

60. Gregory PA, Bracken CP, Bert AG, Goodall GJ. MicroRNAs as regulators of epithelial-mesenchymal transition. Cell Cycle. 2008; 7:3112-3118.

61. Cano A, Nieto MA. Non-coding RNAs take centre stage in epithelial-to-mesenchymal transition. Trends Cell Biol. 2008; 18:357-359.

62. Song C, Liu LZ, Pei XQ, Liu X, Yang L, Ye F, Xie X, Chen J, Tang H, Xie X. miR-200c inhibits breast cancer proliferation by targeting KRAS. Oncotarget. 2015; 6:34968-34978. doi: 10.18632/oncotarget.5198.

63. Sigloch FC, Burk UC, Biniossek ML, Brabletz T, Schilling O. miR-200c dampens cancer cell migration via regulation of protein kinase A subunits. Oncotarget. 2015; 6:2387423889. doi: 10.18632/oncotarget.4381.

64. Gu SQ, Gallego-Perez D, McClory SP, Shi J, Han J, Lee LJ, Schoenberg DR. The human PMR1 endonuclease stimulates cell motility by down regulating miR-200 family microRNAs. Nucleic Acids Res. 2016; 44:5811-5819.

65. Knezevic J, Pfefferle AD, Petrovic I, Greene SB, Perou CM, Rosen JM. Expression of miR-200c in claudinlow breast cancer alters stem cell functionality, enhances chemosensitivity and reduces metastatic potential. Oncogene. 2015; 34:5997-6006.

66. Ye X, Jiang F, Li Y, Mu J, Si L, Wang X, Ning S, Li Z. Glabridin attenuates the migratory and invasive capacity of breast cancer cells by activating microRNA-200c. Cancer science. 2014; 105:875-882.

67. Chang BP, Wang DS, Xing JW, Yang SH, Chu Q, Yu SY. miR-200c inhibits metastasis of breast cancer cells by targeting HMGB1. J Huazhong Univ Sci Technolog Med Sci. 2014; 34:201-206.

68. Bai WD, Ye XM, Zhang MY, Zhu HY, Xi WJ, Huang X, Zhao J, Gu B, Zheng GX, Yang AG, Jia LT. MiR-200c suppresses TGF-beta signaling and counteracts trastuzumab resistance and metastasis by targeting ZNF217 and ZEB1 in breast cancer. International journal of cancer. 2014; $135: 1356-1368$

69. Luo D, Wilson JM, Harvel N, Liu J, Pei L, Huang S, Hawthorn L, Shi H. A systematic evaluation of miRNA:mRNA interactions involved in the migration and invasion of breast cancer cells. J Transl Med. 2013; 11:57.

70. Jurmeister S, Baumann M, Balwierz A, Keklikoglou I, Ward A, Uhlmann S, Zhang JD, Wiemann S, Sahin O. MicroRNA-200c represses migration and invasion of breast cancer cells by targeting actin-regulatory proteins FHOD1 and PPM1F. Mol Cell Biol. 2012; 32:633-651.

71. Howe EN, Cochrane DR, Richer JK. Targets of miR-200c mediate suppression of cell motility and anoikis resistance. Breast Cancer Res. 2011; 13:R45.

72. Cochrane DR, Spoelstra NS, Howe EN, Nordeen SK, Richer JK. MicroRNA-200c mitigates invasiveness and restores sensitivity to microtubule-targeting chemotherapeutic agents. Molecular cancer therapeutics. 2009; 8:1055-1066.

73. Burk U, Schubert J, Wellner U, Schmalhofer O, Vincan E, Spaderna S, Brabletz T. A reciprocal repression between ZEB1 and members of the miR-200 family promotes EMT and invasion in cancer cells. EMBO Rep. 2008; 9:582-589.

74. Korpal M, Lee ES, Hu G, Kang Y. The miR-200 family inhibits epithelial-mesenchymal transition and cancer cell migration by direct targeting of E-cadherin transcriptional repressors ZEB1 and ZEB2. JBiolChem. 2008; 283:14910-14914.

75. Graham TR, Zhau HE, Odero-Marah VA, Osunkoya AO, Kimbro KS, Tighiouart M, Liu T, Simons JW, O'Regan RM. Insulin-like growth factor-I-dependent up-regulation of ZEB1 drives epithelial-to-mesenchymal transition in human prostate cancer cells. Cancer Res. 2008; 68:2479-2488.

76. Drake JM, Barnes JM, Madsen JM, Domann FE, Stipp CS, Henry MD. ZEB1 coordinately regulates laminin-332 and \{beta\} 4 integrin expression altering the invasive phenotype of prostate cancer cells. J Biol Chem. 2010; 285:33940-33948.

77. Kenney PA, Wszolek MF, Rieger-Christ KM, Neto BS, Gould JJ, Harty NJ, Mosquera JM, Zeheb R, Loda M, Darling DS, Libertino JA, Summerhayes IC. Novel ZEB1 expression in bladder tumorigenesis. BJU international. 2011; 107:656-663.

78. Smit MA, Peeper DS. Zeb1 is required for TrkB-induced epithelial-mesenchymal transition, anoikis resistance and metastasis. Oncogene. 2011; 30:3735-3744.

79. Qi S, Song Y, Peng Y, Wang H, Long H, Yu X, Li Z, Fang L, Wu A, Luo W, Zhen Y, Zhou Y, Chen Y, et al. ZEB2 mediates multiple pathways regulating cell proliferation, migration, invasion, and apoptosis in glioma. PloS one. 2012; 7:e38842.

80. Choi SK, Kim HS, Jin T, Hwang EH, Jung M, Moon WK. Overexpression of the miR-141/200c cluster promotes the 
migratory and invasive ability of triple-negative breast cancer cells through the activation of the FAK, PI3K/AKT signaling pathways by secreting VEGF-A. BMC cancer. 2016; 16:570.

81. Shaw FL, Harrison H, Spence K, Ablett MP, Simoes BM, Farnie G, Clarke RB. A detailed mammosphere assay protocol for the quantification of breast stem cell activity. Journal of mammary gland biology and neoplasia. 2012; 17:111-117.

82. Feng ZM, Qiu J, Chen XW, Liao RX, Liao XY, Zhang LP, Chen X, Li Y, Chen ZT, Sun JG. Essential role of miR-200c in regulating self-renewal of breast cancer stem cells and their counterparts of mammary epithelium. BMC cancer. 2015; 15:645.

83. Chang CJ, Chao CH, Xia W, Yang JY, Xiong Y, Li CW, Yu WH, Rehman SK, Hsu JL, Lee HH, Liu M, Chen CT, Yu D, et al. p53 regulates epithelial-mesenchymal transition and stem cell properties through modulating miRNAs. Nat Cell Biol. 2011; 13:317-323.

84. Weidner N, Semple JP, Welch WR, Folkman J. Tumor angiogenesis and metastasis--correlation in invasive breast carcinoma. The New England journal of medicine. 1991; 324:1-8.

85. Dales JP, Garcia S, Carpentier S, Andrac L, Ramuz O, Lavaut MN, Allasia C, Bonnier P, Charpin C. Long-term prognostic significance of neoangiogenesis in breast carcinomas: comparison of Tie-2/Tek, CD105, and CD31 immunocytochemical expression. Hum Pathol. 2004; 35:176-183.

86. Mineo TC, Ambrogi V, Baldi A, Rabitti C, Bollero P, Vincenzi B, Tonini G. Prognostic impact of VEGF, CD31, CD34, and CD105 expression and tumour vessel invasion after radical surgery for IB-IIA non-small cell lung cancer. Journal of clinical pathology. 2004; 57:591-597.

87. Zhang HF, Xu LY, Li EM. A family of pleiotropically acting microRNAs in cancer progression, miR-200: potential cancer therapeutic targets. Curr Pharm Des. 2014; 20:1896-1903.

88. Matsumoto K, Ema M. Roles of VEGF-A signalling in development, regeneration, and tumours. J Biochem. 2014; 156:1-10.

89. Shibuya M. Vascular endothelial growth factor and its receptor system: physiological functions in angiogenesis and pathological roles in various diseases. J Biochem. 2013; 153:13-19.

90. Lee TH, Seng S, Sekine M, Hinton C, Fu Y, Avraham HK, Avraham S. Vascular endothelial growth factor mediates intracrine survival in human breast carcinoma cells through internally expressed VEGFR1/FLT1. PLoS medicine. 2007; 4:e186.

91. Taylor AP, Goldenberg DM. Role of placenta growth factor in malignancy and evidence that an antagonistic PlGF/Flt-1 peptide inhibits the growth and metastasis of human breast cancer xenografts. Molecular cancer therapeutics. 2007; 6:524-531.

92. Pecot CV, Rupaimoole R, Yang D, Akbani R, Ivan C, Lu C, Wu S, Han HD, Shah MY, Rodriguez-Aguayo C, BottsfordMiller J, Liu Y, Kim SB, et al. Tumour angiogenesis regulation by the miR-200 family. Nature communications. $2013 ; 4: 2427$.

93. Borgan E, Lindholm EM, Moestue S, Maelandsmo GM, Lingjaerde OC, Gribbestad IS, Borresen-Dale AL, Engebraaten O, Sorlie T. Subtype-specific response to bevacizumab is reflected in the metabolome and transcriptome of breast cancer xenografts. Molecular oncology. 2013; 7:130-142.

94. Chang H, Jeung HC, Jung JJ, Kim TS, Rha SY, Chung HC. Identification of genes associated with chemosensitivity to SAHA/taxane combination treatment in taxane-resistant breast cancer cells. Breast Cancer Res Treat. 2011; 125:55-63.

95. He L, Lu Y, Wang P, Zhang J, Yin C, Qu S. Up-regulated expression of type II very low density lipoprotein receptor correlates with cancer metastasis and has a potential link to beta-catenin in different cancers. BMC cancer. 2010; 10:601.

96. Li J, Liu Y, Yin Y. Inhibitory effects of Arhgap6 on cervical carcinoma cells. Tumour biology: the journal of the International Society for Oncodevelopmental Biology and Medicine. 2016; 37:1411-1425.

97. Davies S, Dai D, Pickett G, Thiel KW, Korovkina VP, Leslie KK. Effects of bevacizumab in mouse model of endometrial cancer: Defining the molecular basis for resistance. Oncology reports. 2011; 25:855-862.

98. Klein JD, Sands JM. Urea transport and clinical potential of urearetics. Curr Opin Nephrol Hypertens. 2016; 25:444-451.

99. Matsuda K, Takahashi A, Middlebrooks CD, Obara W, Nasu Y, Inoue K, Tamura K, Yamasaki I, Naya Y, Tanikawa C, Cui R, Figueroa JD, Silverman DT, et al. Genome-wide association study identified SNP on 15q24 associated with bladder cancer risk in Japanese population. Human molecular genetics. 2015; 24:1177-1184.

100. Vaarala MH, Hirvikoski P, Kauppila S, Paavonen TK. Identification of androgen-regulated genes in human prostate. Molecular medicine reports. 2012; 6:466-472.

101. Watson KL, Moorehead RA. Loss of Akt1 or Akt2 delays mammary tumor onset and suppresses tumor growth rate in MTB-IGFIR transgenic mice. BMC cancer. 2013; 13:375.

102. Bolger AM, Lohse M, Usadel B. Trimmomatic: a flexible trimmer for Illumina sequence data. Bioinformatics. 2014; 30:2114-2120.

103. Dobin A, Davis CA, Schlesinger F, Drenkow J, Zaleski C, Jha S, Batut P, Chaisson M, Gingeras TR. STAR: ultrafast universal RNA-seq aligner. Bioinformatics. 2013; 29:15-21. 
104. Roberts A, Pimentel H, Trapnell C, Pachter L. Identification of novel transcripts in annotated genomes using RNA-Seq. Bioinformatics. 2011; 27:2325-2329.

105. Anders S, Huber W. Differential expression analysis for sequence count data. Genome biology. 2010; 11:R106.

106. Robinson MD, McCarthy DJ, Smyth GK. edgeR: a Bioconductor package for differential expression analysis of digital gene expression data. Bioinformatics. 2010; 26:139-140.

107. Jones RA, Campbell CI, Petrik JJ, Moorehead RA. Characterization of a novel primary mammary tumor cell line reveals that cyclin D1 is regulated by the type I insulin-like growth factor receptor. MolCancer Res. 2008; 6:819-828. 